Meteorol. Atmos. Phys. 42, 197-219 (1990)

Meteorology and Atmospheric Physics

(C) by Springer-Verlag 1990

\title{
Three-Dimensional Modeling of Synthetic Cold Fronts Approaching the Alps
}

\section{Heimann}

With 12 Figures

Received January 15,1990

\section{Summary}

A numerical model was used to study the behaviour of prototype cold fronts as they approach the Alps. Two fronts with different orientations relative to the Alpine range have been considered. One front approaches from west, a second one from northwest. The first front is connected with southwesterly large-scale air-flow producing pre-frontal foehn, whereas the second front is associated with westerly largescale flow leading to weak blocking north of the Alps.

Model simulations with fully represented orography and parameterized water phase conversions have been compared with control runs where either the orography was cut off or the phase conversions were omitted. The results show a strong orographic influence in case of pre-frontal foehn which warms the pre-frontal air and increases the cross-frontal temperature contrast leading to an acceleration of the front along the northern Alpine rim. The latent heat effect was found to depend much on the position of precipitation relative to the surface front line. In case of pre-frontal foehn precipitation only falls behind the surface front line into the intruding cold air where it partly evaporates. In contrary, precipitation already appears ahead of the front in the case of blocking. Thus, the cooling effect of evaporating rain increases the cross-frontal temperature difference only in the first case causing an additional acceleration of the front.

\section{List of symbols:}

$\begin{array}{ll}c_{p d} & \text { specific heat capacity of dry air at cons- } \\ & \text { tant pressure }\left(c_{p d}=1004.71 \mathrm{~J} \mathrm{~kg}^{-1} \mathrm{~K}^{-1}\right) \\ & \text { specific heat capacity of water vapour at } \\ c_{p y} & \text { constant pressure }\left(c_{p v}=1845.96 \mathrm{~J} \mathrm{~kg}^{-1} \mathrm{~K}^{-1}\right) \\ & \text { propagation speed of a front } \\ c_{F} & \text { horizontal grid spacing (cartesian system) }\end{array}$

$\begin{array}{ll}\Delta \lambda, \Delta \varphi & \text { horizontal grid spacing (geographic system) } \\ \Delta t & \text { time step } \\ E & \text { turbulent kinetic energy } \\ f & \text { Coriolis parameter } \\ g & \text { gravity acceleration }\left(g=9.81 \mathrm{~m} \mathrm{~s}^{-1}\right) \\ h & \text { terrain elevation } \\ H & \text { height of model lid }(H=9000 \mathrm{~m}) \\ k & \text { Karman constant }(k=0.4) \\ K_{M h} & \text { horizontal exchange coefficient of momentum } \\ K_{H h} & \text { horizontal exchange coefficient of heat and } \\ & \text { moisture } \\ K_{M z} & \text { vertical exchange coefficient of momentum } \\ K_{H z} & \text { vertical exchange coefficient of heat and } \\ & \text { moisture } \\ \ell & \text { mixing length } \\ \ell_{c} & \text { specific condensation heat }\left(\ell_{c}=2500.61 \mathrm{~kJ}\right. \\ & \text { kg-1) } \\ \ell_{f} & \text { specific freezing heat }\left(\ell_{f}=333.56 \mathrm{~kJ} \mathrm{~kg}^{-1}\right) \\ \ell_{s} & \text { specific sublimation heat }\left(\ell_{s}=2834.17 \mathrm{~kJ}\right. \\ \lambda & \text { kg-1) } \\ m_{1}, m_{2}, m_{3} & \text { longitude } \\ p & \text { metric coefficients } \\ \pi & \text { pressure } \\ P r & \text { Exner function } \\ \varphi & \text { Prandtl number } \\ \varphi_{M} & \text { latitude } \\ q_{v} & \text { profile function } \\ q_{c} & \text { specific humidity } \\ q_{i} & \text { specific content of cloud droplets } \\ q_{R} & \text { specific content of cloud ice particles } \\ q_{S} & \text { specific content of rain drops } \\ R_{d} & \text { specific content of snow } \\ & \text { gas constant of dry air }\left(R_{d}=287.06 \mathrm{~J}\right. \\ R_{v} & \left.\text { kg } \mathrm{K}^{-1}\right) \\ & \text { gas constant of water vapour }\left(R_{v}=461.51 \mathrm{~J}\right. \\ \left.\text { kg-1 } \mathrm{K}^{-1}\right) \\ \end{array}$




$\begin{array}{ll}r_{E} & \text { radius of earth }\left(r_{E}=6371 \mathrm{~km}\right) \\ R i_{F} & \text { flux Richardson number } \\ \rho & \text { density of dry air } \\ t & \text { time } \\ T & \text { temperature } \\ \tau_{d i a} & \text { period of diastrophy } \\ \Theta & \text { potential temperature } \\ \Theta_{v} & \text { virtual potential temperature } \\ \Theta_{e} & \text { equivalent potential temperature } \\ U & \text { relative humidity } \\ u, v, w & \text { cartesian wind components } \\ u_{F}, v_{F} & \text { front-normal and front-parallel wind } \\ x, y, z & \text { components } \\ w^{*} & \text { cartesian coordinates } \\ W_{R} & \text { transformed vertical wind component } \\ W_{S} & \text { speed of falling rain } \\ z^{*} & \text { speed of falling snow }\end{array}$

Abbreviations

GND (above) ground level

MSL (above) mean sea level

\section{Introduction}

Cold fronts are often strongly modified as they cross major mountain ranges like the Alps in Central Europe. The orographically induced distortion of cold fronts approaching the Alps was analyzed and illustrated by isochrones for instance by Steinacker (1981), Kurz (1984), Heimann and Volkert (1988). Further investigations have been carried out in connection with the German Front Experiment 1987 (refered to as GFE 87 in the following; for details see Hoinka and Volkert, 1987) during which five frontal events were observed in detail. Evaluations of measurements gained during this campaign revealed mesoscale features of cold fronts as they moved towards the Alps. An overview of preliminary results is given by Hoinka et al. (1988). It came out that these fronts appeared very differently according to their orientation and their synoptic scale environment. The front of 8 October 1987, for instance, was almost southnorth orientated and passed the Alpine foreland without precipitation although it had been connected with rain over southwestern Germany. A mesoscale gravity current like structure developed at this front near the Alps after the precipitation had stopped (Hoinka et al., 1990 and Kurz, 1989). In contrary, the front of 19 December 1987 approached the Alps from northwest. It was accom- panied by a narrow band of intense precipitation embedded in a larger area of rain covering southern Bavaria almost entirely (Hagen, 1989). Both fronts were retarded at the Alps and thus the surface front lines were bended along the Alpine bow. Additionally, there is some evidence that the observed mesoscale features have been caused or at least modified by the orography. Observations, also if sampled in dense temporal sequence and spatial distribution, only represent the combined effect of all interactions and influences envolved. Numerical modeling, instead, enables a separation of single effects. Therefore, it may contribute to a further understanding of the relevant processes, and it may support the interpretation of phenomena which were observed during GFE 87.

The numerical study presented here does not intend to simply imitate observed events. It is rather designed to investigate the behaviour of synthetic fronts which are comparable among each other due to identical, though realistic parameter configurations. Stimulated by the above mentioned events of GFE 87 the numerical experiments consider two differently orientated fronts. One front approaches from the west, the other one from northwest. In both cases the direction of the super-imposed large-scale flow is directly related to the frontal orientation by a prescribed angle of $60^{\circ}$ to the surface front line. Thus, the first front has a south-westerly flow ahead, which generates pre-frontal foehn north of the Alps, whereas the second front is connected with a westerly flow and has no pre-frontal foehn associated with. But unlike the observed cases the synthetic ones do not differ in other aspects, like large-scale air speed, static stability, temperature contrast across the fronts, or moisture content of the relevant air masses.

This strategy offers the possibility to separate the influence of the frontal orientation. Additional runs with an artificial cut-off orography or turned off water phase conversions provide specific knowledge about the effects of foehn and latent heat conversions on the fronts.

The paper is organized as follows: Chapter 2 describes the numerical model. Chapter 3 deals with principal mechanisms of latent heat on cold fronts. It presents the results of two-dimensional simulations which allow to isolate the pure effect of water phase conversions on a moving frontal system. The combined effects of the real Alpine 
orography and moisture processes are discussed in Chapter 4. Two characteristic frontal systems are investigated by three-dimensional numerical simulations. The last section of this chapter addresses the different appearance of both synthetic frontal systems as they are simulated overhead the location of München. Conclusions are given in Chapter 5.

\section{The Numerical Model}

The scale of interest is subsynoptic and can be classified as meso- $\alpha$ using Orlanski's (1975) definition. For this scale the hydrostatic model approximation seems to be fully justified. The model used in this study does not differ much from other hydrostatic mesoscale models which are prevalent as regional weather forecast tools. The model contains parameterization schemes to account for turbulent diffusion and water phase conversions.

\subsection{Model Equations}

The model equations describe a hydrostatic and anelastic atmosphere without scale separations, i.e. no geostrophic wind is extracted from the pressure forcing term. The equations are formulated in a $\lambda, \varphi, z^{*}$-grid system. $\lambda$ and $\varphi$ are the geographical coordinates, i.e. longitude and latitude. They have been used for convenience, since the orographic data base was available in this system only. $\lambda$ and $\varphi$ can be converted to the cartesian $x$ and $y$ coordinates by

$x=\frac{\lambda}{m_{1}}$

$y=\frac{\varphi}{m_{2}}$

with

$m_{1}=\left(r_{E} \cdot \cos \varphi\right)^{-1}$

$m_{2}=r_{E}^{-1}$

Additional metric terms appear in the equations of motion and in the equation of continuity, which account for the curvature of latitudes and convergence of longitudes, respectively. These terms carry the factor

$m_{3}=\frac{\tan \varphi}{r_{E}}$

tween $z^{*}=0$ at the earth's surface $(z=h)$ and $z^{*}=1$ at the top of the model atmosphere $(z=H)$.

The relationship between $z$ and $z$ reads

$z^{*}=\frac{z-h}{H-h}$

- Equations of motion:

$$
\begin{aligned}
\frac{\partial u}{\partial t}= & -u m_{1} \frac{\partial u}{\partial \lambda}-v m_{2} \frac{\partial u}{\partial \varphi} \\
& -w^{*} \frac{\partial u}{\partial z^{*}}+u v m_{3} \\
& +f v-g \frac{1-z^{*}}{H-h} m_{1} \frac{\partial h}{\partial \lambda} \\
& -c_{p d} \Theta_{v} m_{1} \frac{\partial \pi}{\partial \lambda} \\
& +\frac{1}{(H-h)^{2}} \frac{\partial}{\partial z^{*}} K_{M z} \frac{\partial u}{\partial z^{*}} \\
& +K_{M h}\left(m_{1}{ }^{2} \frac{\partial^{2} u}{\partial \lambda^{2}}+m_{2}{ }^{2} \frac{\partial^{2} u}{\partial \varphi^{2}}\right)
\end{aligned}
$$

$$
\begin{aligned}
\frac{\partial v}{\partial t}= & -u m_{1} \frac{\partial v}{\partial \lambda}-v m_{2} \frac{\partial v}{\partial \varphi} \\
& -w^{*} \frac{\partial v}{\partial z^{*}}-u^{2} m_{3} \\
& -f u-g \frac{1-z^{*}}{H-h} m_{2} \frac{\partial h}{\partial \varphi} \\
& -c_{p d} \Theta_{v} m_{2} \frac{\partial \pi}{\partial \varphi} \\
& +\frac{1}{(H-h)^{2}} \frac{\partial}{\partial z^{*}} K_{M z} \frac{\partial v}{\partial z^{*}} \\
& +K_{M h}\left(m_{1}{ }^{2} \frac{\partial^{2} v}{\partial \lambda^{2}}+m_{2}{ }^{2} \frac{\partial^{2} v}{\partial \varphi^{2}}\right)
\end{aligned}
$$

\section{- Equation of continuity:}

The equation of continuity is given in its anelastic form:

$$
\begin{aligned}
& \frac{\partial \rho w^{*}}{\partial z^{*}}=-m_{1} \frac{\partial \rho u}{\partial \lambda}-m_{2} \frac{\partial \rho v}{\partial \varphi} \\
& +\frac{1}{H-h}\left(\rho u m_{1} \frac{\partial h}{\partial \lambda}+\rho v m_{2} \frac{\partial h}{\partial \varphi}\right)+\rho v m_{3}
\end{aligned}
$$


where $w^{*}$ is the transformed vertical component of the wind velocity. It is related to the cartesian vertical component $w$ by

$$
\begin{aligned}
w & =(H-h) w^{*} \\
& +\left(1-z^{*}\right)\left(u m_{1} \frac{\partial h}{\partial \lambda}+v m_{2} \frac{\partial h}{\partial \varphi}\right)
\end{aligned}
$$

- Hydrostatic equation:

$\frac{\partial \pi}{\partial z}=-\frac{g}{c_{p d} \Theta_{v}}$

- Temperature equation:

$$
\begin{aligned}
\frac{\partial \Theta}{\partial t}= & -u m_{1} \frac{\partial \Theta}{\partial \lambda}-v m_{2} \frac{\partial \Theta}{\partial \varphi}-w^{*} \frac{\partial \Theta}{\partial z^{*}} \\
& +\frac{1}{(H-h)^{2}} \frac{\partial}{\partial z^{*}} K_{H z} \frac{\partial \Theta}{\partial z^{*}} \\
& +K_{H h}\left(m_{1}{ }^{2} \frac{\partial^{2} \Theta}{\partial \lambda^{2}}+m_{2}{ }^{2} \frac{\partial^{2} \Theta}{\partial \varphi^{2}}\right)+\left.\frac{\partial \Theta}{\partial t}\right|_{\text {lat }}
\end{aligned}
$$

The last term represents the latent heat exchange due to phase conversions of atmospheric water. Radiation processes, however, are neglected throughout this study.

\subsection{General Definitions}

- Coriolis parameter:

$f(\varphi)=f_{0} \cdot \sin \varphi ; \quad f_{0}=1.4584 \cdot 10^{-4} \mathrm{~s}^{-1}$

- Exner function:

$\pi=\left(p / p_{0}\right)^{R_{d} / c_{p d}} ; \quad p_{0}=10^{5} \mathrm{~Pa}$

\section{- Potential temperature:}

$\Theta=T \pi^{-1}$

- Virtual potential temperature:

$\Theta_{v}=\Theta\left(1+\left[\frac{R_{v}-R_{d}}{R_{d}}\right] q_{v}\right)$

\subsection{Turbulence Parameterization Scheme}

Sub-grid scale processes are treated identically to those in the FITNAH model, cf. Gross and Wippermann (1987). The turbulence parameterization scheme is based on a prognostic equation for the turbulent kinetic energy $E$ as proposed by Yamada (1983).

$$
\begin{aligned}
\frac{\partial E}{\partial t}= & -u m_{1} \frac{\partial E}{\partial \lambda}-v m_{2} \frac{\partial E}{\partial \varphi}-w^{*} \frac{\partial E}{\partial z^{*}} \\
& +\frac{K_{M z}}{(H-h)^{2}}\left[\left(\frac{\partial u}{\partial z^{*}}\right)^{2}+\left(\frac{\partial v}{\partial z^{*}}\right)^{2}\right] \times\left(1-R i_{F}\right) \\
& +\frac{1.2}{(H-h)^{2}} \frac{\partial}{\partial z^{*}} K_{H z} \frac{\partial E}{\partial z^{*}} \\
& -0.08 \cdot \varphi_{M} \cdot \frac{E^{3 / 2}}{\ell}
\end{aligned}
$$

The dissipation rate of $E$ depends on a length scale $\ell$, which is calculated using Blackadar's (1962) mixing length formula.

$$
\begin{gathered}
\ell=\frac{k z^{*}(H-h)}{1+\frac{k z^{*}(H-h)}{\ell_{\infty}}} ; \quad \ell_{\infty}=30 \mathrm{~m} ; \\
k=0.4
\end{gathered}
$$

Profile functions after Businger et al. (1971) are determined locally

$$
\begin{array}{ll}
\varphi_{M}=1+4.7 R i_{F} & \text { for } \partial \Theta / \partial z^{*} \geqslant 0 \\
\left.\varphi_{M}=1-15 R i_{F}\right)^{-0.25} & \text { for } \partial \Theta / \partial z^{*}<0
\end{array}
$$

with the flux Richardson number

$$
R i_{F}=\frac{H-h}{\operatorname{Pr}} \frac{g}{\Theta} \frac{\frac{\partial \Theta}{\partial z^{*}}}{\left(\frac{\partial V}{\partial z^{*}}\right)^{2}} ; \quad V=\sqrt{u^{2}+v^{2}}
$$

and the Prandtl number

$$
\begin{aligned}
& \operatorname{Pr}=1 \\
& \quad \text { for } z(H-h) \geqslant z_{D} \\
& \operatorname{Pr}=\left(1.35-0.35 z^{*}(H-h) / z_{D}\right)^{-1} \\
& \quad \text { for } z^{*}(H-h)<z_{D} \\
& z_{D}=1000 \mathrm{~m}
\end{aligned}
$$


The vertical exchange coefficients are then determined by

$K_{M z}=0.45 \cdot \varphi_{M}^{-2} \cdot E^{0.5}$

$K_{H z}=\frac{K_{M z}}{P r}$

The horizontal exchange coefficients mainly serve for smoothing in a damping layer beneath the model lid rather than for sub-grid scale parameterization

$$
\begin{aligned}
& K_{M h}=\max \left[10 \mathrm{~m}^{2} / \mathrm{s}, \frac{z^{*}-z^{*} T}{1-z_{T}^{*}} K_{T}\right] \\
& K_{H h}=\max \left[0, \frac{z^{*}-z^{*} T_{T}}{1-z_{T}^{*}} K_{T}\right]
\end{aligned}
$$

where $z_{T}{ }_{T}$ is the lower limit of the damping layer, which reaches up to the model lid

at $z=H$.

$z^{*}{ }_{T}=0.75 ; \quad K_{T}=5 \cdot 10^{5} \mathrm{~m}^{2} / \mathrm{s}$

The evaluation of model results is restricted to altitudes below the damping layer.

\subsection{Moisture Processes}

The transport and conversion of water vapour, cloud droplets, cloud ice, rain, and snow, is optionally considered in the model. If invoked, the specific humidities are conserved by the following equations.

$$
\begin{aligned}
\frac{\partial q_{w}}{\partial t}= & -u m_{1} \frac{\partial q_{w}}{\partial \lambda}-v m_{2} \frac{\partial q_{w}}{\partial \varphi} \\
& -w^{*} \frac{\partial q_{w}}{\partial z^{*}}-W_{w} \frac{\partial q_{w}}{\partial z} \\
& +\frac{1}{(H-h)^{2}} \frac{\partial}{\partial z^{*}} K_{H z} \frac{\partial q_{w}}{\partial z^{*}} \\
& +K_{H h}\left(m_{1}{ }^{2} \frac{\partial^{2} q_{w}}{\partial \lambda^{2}}+m_{2}{ }^{2} \frac{\partial^{2} q_{w}}{\partial \varphi^{2}}\right) \\
& +\left.\frac{\partial q_{w}}{\partial t}\right|_{\text {mic }}
\end{aligned}
$$

where $q_{w}$ are specific contents of water vapour cloud droplets

cloud ice

rain drops

snow flakes
$W_{w}$ are the terminal velocities of the respective constituents. For water vapour and cloud particles they are set to zero, i.e. $W_{v}=W_{c}=W_{i}=0$. The terminal velocities for rain and snow, $W_{R}$ and $W_{S}$, are given by Lin et al. (1983).

$\partial q_{w} / \partial t_{\text {mic }}$ represents the conversion rates of the respective constituent $q_{w}$.

The micro-physical scheme is based on a summary given by Pielke (1984, p. 232-238). He proposed formulas by Kessler (1969), Chang (1977), Orville (1980), and Lin et al. (1983). Few of them have been slightly modified or have been replaced by similar formulas given by Höller (1986).

The following processes are considered:

$$
\begin{aligned}
& \left.\frac{\partial q_{v}}{\partial t}\right|_{\text {mic }}=-S_{c}-S_{s}-P_{S 4}+P_{R 3} \\
& \left.\frac{\partial q_{c}}{\partial t}\right|_{\text {mic }}=+S_{c}-S_{f}-P_{S 3}-P_{R 1}-P_{R 2} \\
& \left.\frac{\partial q_{i}}{\partial t}\right|_{\text {mic }}=+S_{s}+S_{f}-P_{S 1}-P_{S 2} \\
& \left.\frac{\partial q_{R}}{\partial t}\right|_{m i c}=-P_{S 5}+P_{R 1}+P_{R 2}-P_{R 3} \\
& \left.\frac{\partial q_{S}}{\partial t}\right|_{\text {mic }}=+P_{S 1}+P_{S 2}+P_{S 3}+P_{S 4}+P_{S 5}
\end{aligned}
$$

The single conversion rates have the following meanings:

$S_{c}$ condensation of water vapour to cloud droplets $\left(S_{c}>0\right)$ or evaporation of cloud droplet $\left(S_{c}<0\right)$

$S_{s}$ sublimation of water vapour to cloud ice $\left(S_{s}>0\right)$ or evaporation of cloud ice $\left(S_{s}<0\right)$

$S_{f}$ freezing of cloud droplets to cloud ice $\left(S_{f}>0\right)$ or melting fo cloud ice to cloud droplets $\left(S_{f}<0\right)$

$P_{R 1}$ autoconversion of cloud droplets to form rain drops $\left(P_{R 1} \geqslant 0\right)$

$P_{R 2}$ accretion of cloud droplets by rain drops $\left(P_{R 2} \geqslant 0\right)$

$P_{R 3}$ evaporation of rain drops in subsaturated ambient air $\left(P_{R 3} \geqslant 0\right)$

$P_{S 1}$ autoconversion of cloud ice to form snow flakes $\left(\mathrm{P}_{S 1} \geqslant 0\right)$

$P_{S 2}$ accretion of cloud ice by snow $\left(P_{S 2} \geqslant 0\right)$

$P_{S 3}$ accretion of cloud droplets by snow $\left(P_{S 3} \geqslant 0\right)$ 
$P_{S 4}$ depositional growth $\left(P_{S 4}>0\right)$ or evaporational loss $\left(P_{S 4}<0\right)$ of snow

$P_{S 5} \quad$ melting of snow to form rain $\left(P_{S 5} \leqslant 0\right)$

The phase conversions of atmospheric water lead to the following diabatic heat exchanges:

$$
\begin{aligned}
\left.\frac{\partial \Theta}{\partial t}\right|_{l a t} & =\left[\ell_{s} \cdot\left(S_{s}+P_{S 4}\right)+\ell_{c} \cdot\left(\mathrm{S}_{c}-P_{R 3}\right)\right. \\
& \left.+\ell_{f} \cdot\left(S_{f}+P_{S 5}+P_{S 3}\right)\right] \cdot \frac{\Theta}{c_{p d} T}
\end{aligned}
$$

This term acts in the temperature Eq. (6) if moisture processes are invoked, otherwise it vanishes.

\subsection{Numerical Procedure, Initialization, and Boundary Conditions}

The model uses a staggered grid. All scalars are defined at the mesh volume centers, whereas the wind components are placed at the center of the respective inflow walls of each mesh volume. The scalars are also defined at the earth's surface and at the model top.

Foreward time steps are employed for temporal integration. In the advective terms of Eqs. (1) and (2) spatial derivatives are approximated by simple upstream differences. The advection terms in Eqs. (6), (8), and (11) are solved with an upstreamspline procedure after Mahrer and Pielke (1978) to reduce spurious diffusion. The velocity components of the "new" time step govern the advection in the scalar equations.

All spatial derivatives in non-advection terms are approximated by centered differences.

The numerical integration starts with a geostrophically balanced, frictionless wind field over homogeneous terrain. The initial momentum is introduced by prescribing a horizontal "suprascale" pressure gradient at the top of the model, i.e. at $z^{*}=1$. The geostrophic wind is then calculated from the three-dimensional pressure field gained by downward integration of the hydrostatic Eq. (5).

During the first hour of integration $\left(0 \leqslant t \leqslant \tau_{d i a}=1 \mathrm{~h}\right)$ the orography is smoothly added by "diastrophy", i.e. by inflating the mountain linearly with time. The process of diastrophy itself does not change the vertical stratification of temperature and humidity. This is ensured by an additional term in the equations of temperature
(6) and specific humidity (11), which only acts during the period of diastrophy. This term reads

$\left.\frac{\partial a}{\partial t}\right|_{d i a}=\frac{\left(1-z^{*}\right) h}{\tau_{d i a} H-t h} \cdot \frac{\partial a}{\partial z^{*}}$

for $0 \leqslant t \leqslant \tau_{\text {dia }}$ and $a=\left(\Theta, q_{v}\right) . h$ is the final terrain elevation.

All friction terms are set to zero at $t=0$. During the period of diastrophy they are activated linearly with time until they act with full efficiency for $t>\tau_{\text {dia }}$.

At the lateral boundaries tendencies of all prognostic model parameters with the exception of $\Theta$ and $q_{\nu}$ are determined using radiative conditions. $\Theta$ and $q_{v}$ are treated specially to simulate the intrusion of an undersaturated cold air mass from outside the domain. The corresponding procedure is explained in Section 2.6. The radiative boundary condition follows a suggestion fo Orlanski (1976) and is examplarily sketched for the western boundary $(i=1)$ at time level $v$ :

$a_{i=1}^{p}=-c_{a} \frac{a_{i=2}^{v-1}-a_{i=1}^{y-1}}{\Delta x} \cdot \Delta t+a_{i=1}^{y=1}$

with

$c_{a}=\min \left[-\frac{a_{i=2}^{v}-a_{i=2}^{\nu-1}}{a_{i=3}^{v-1}-a_{i=1}^{v-1}} \cdot \frac{2 \Delta x}{\Delta t}, 0\right]$

and $a=\left(u, v, q_{c}, q_{i}, q_{R}, q_{S}, E\right)$.

At the top of the model $(z=H)$ a permeable lid is assumed. A zero-gradient condition is applied for $u, v$, and the radiative condition for $\Theta$ and $q_{v}$. The specific contents of water constituents other than water vapour, i.e. $q_{c}, q_{i}, q_{R}, q_{S}$, as well as the turbulent kinetic energy $E$ are set to zero. The Exner function varies during one time step by $\Delta \pi$ due to a change of virtual potential temperature $\Delta \Theta_{v}=\Delta z \cdot \gamma_{v}$ caused by an advective vertical displacement $\Delta z=|w| \cdot \Delta t . w$ and $\gamma_{v}$ are the vertical velocity and the vertical gradient of $\Theta_{y}$ at $z=H$, respectively. $\Delta \pi$ is given by

$\Delta \pi=\Delta z \cdot \frac{g}{c_{p d}} \cdot \frac{\Delta \Theta_{v}}{2 \Theta_{v}^{2}}$

At the surface $\left(z=h, z^{*}=0\right)$ zero-gradient conditions are set for $\Theta, q_{v}, q_{c}, q_{i}, q_{R}$, and $q_{S}$. All velocity components $\left(u, v, w^{*}\right)$ and the turbulent kinetic energy $(E)$ vanish. 


\subsection{Representation of a Cold Front in the Model}

At the time of initialization $(t=0)$ most of the model atmosphere is filled with a "warm air" mass, characterized by prescribed vertical profiles of potential temperature $\Theta_{\text {warm }}\left(z^{*}\right)$ and specific humidity $q_{v, \text { warm }}\left(z^{*}\right)$. In the inflow area of the model domain the "warm air" profiles are replaced by "cold air" profiles $\Theta_{\text {cold }}\left(z^{*}\right)$ and $q_{v, \text { cold }}\left(z^{*}\right)$ beneath an inclined surface $H_{F}$, which intersects the model's bottom $\left(z^{*}=0\right)$ along a prescribed line. This surface represents a frontal surface at the time of initialization. Its intersection with the model's bottom defines a surface frontline. The frontal surface separates both air masses. Since the initial air masses are defined to be horizontally homogeneous, the only horizontal gradients of $\Theta$ and $q_{v}$ concentrate on the frontal surface, which is, of course, a thin layer in the model due to the finite spacing of the numerical grid.

If $\xi$ is a horizontal coordiante perpendicular to the surface front-line with $\xi=0$ at this line, the height of the frontal surface is defined by a formula given by Davies (1984):

$H_{F}(\xi)=\mathrm{H}_{F, \infty} \cdot\left[1-\exp \left(-\frac{f \xi}{\sqrt{g^{\prime} H_{F, \infty}}}\right)\right]$

with

$g^{\prime}=g \cdot \frac{\Theta_{\text {warm }}-\Theta_{\text {cold }}}{\Theta_{\text {cold }}}$

$H_{F, \infty}$ is the prescribed height of the frontal surface which is reached assymptotically far upstream of the surface front-line.

During temporal integration the vertical profiles of potential temperature and specific humidity are explicitly set at the boundary grid cells to allow for cold air advection from outside. $H_{F}$ is calculated analytically at these cells by

$H_{F}(t)=\mathrm{H}_{F, \infty} \cdot\left[1-\exp \left(-\frac{f\left(\xi_{0}+\dot{\xi}_{g} \cdot t\right)}{\sqrt{g^{\prime} H_{F, \infty}}}\right)\right]$

with $\xi_{o}$ as the distance of the respective boundary cell centers from the initial surface front-line position and $\dot{\xi}_{g}$ as the initial geostrophic wind component in the warm air mass perpendicular to the initial surface front-line. Beneath $H_{F}$ the cold air profiles $\left(\Theta_{\text {cold }}\left(z^{*}\right), q_{v \text {, cold }}\left(z^{*}\right)\right)$, above it the warm air profiles $\left(\Theta_{\text {warm }}\left(z^{*}\right), q_{v, \text { warm }}\left(z^{*}\right)\right)$ are prescribed as a lateral boundary condition. Thus, the depth of the intruding cold air increases continuously at the model's inflow boundaries as time goes on. In this point the study differs from numerical investigations presented by Garratt and Physick (1986) who employed a cold air reservoir of constant vertical and horizontal extension at the inflow boundary.

\section{Principal Mechanisms of Latent Heat Effects on Cold Fronts}

\subsection{Theoretical Considerations}

The behaviour of cold fronts and also that of gravity currents is strongly influenced by the stratification of the air masses involved and by the temperature contrast between them. In the following we concentrate on two characteristics of a front, namely its steady speed of propagation over a plain, and its changed speed across or along a mountain range.

In case of a laboratory gravity current in a rotational system the propagation speed is given by Stern et al. (1982):

$c_{F}=0.5 \cdot u_{\infty}+g^{\prime} \cdot \frac{h_{\infty}}{u_{\infty}}$

$u_{\infty}$ and $h_{\infty}$ are the cross-frontal wind component and the cold air thickness far behind the front. $g^{\prime}$ is the reduced acceleration of gravity $g^{\prime}=g \Delta \Theta /$ $\Theta$, where $\Delta \Theta$ is the difference of potential temperature between the two fluids. Hence, the greater $\Delta \Theta$ the faster the system moves.

Davies (1984) used an analytical two-layer model of neutrally stratified air masses to demonstrate that the greater the thermal contrast the more a cold front would be retarded by a mountain range. An extended numerical inspection of orographic impacts on idealized fronts was published by Schumann (1987). He defined a set of dimensionless parameters which describe whether fronts are blocked at mountains or not. Egger and Haderlein (1986) expect from model calculations that a cold front which is hindered to cross a mountain range forms an "orographic jet", i.e. an accelerated flow parallel to the mountain range. The front-like nose of this jet behaves like a trapped gravity current. Thus, its speed depends on the magnitude of the density jump or temperature contrast. Such orographic jets are sometimes observed. Heimann and Volkert (1988), for instance, 
analyzed a remarkable event near the Alps. Numerical studies of this case have been presented by Heimann (1988) and Volkert et al. (1990).

Bannon (1984) studied the appearance of model fronts with respect to their ambient air stratification. He found that fronts are weaker, have less steep frontal surfaces, and move more slowly in an environment of strong static stability. In contrary, Bischoff-Gauss and Gross (1989) found a faster propagation of a numerically simulated gravity current moving in stably stratified warm air compared to that moving in neutral environment. The authors partly explained this behaviour by an enlarged temperature deficit of the cold air, which they let originate in a neutrally stratified reservoir in either case.

However, both, stratification and cross-frontal thermal contrast, will be modified by latent heat effects. As a consequence, one can expect evident impacts on cold fronts concerning their propagation speed as well as their behaviour near mountains.

If the warm air is moist enough, condensation will take place due to lifting near the front. This leads to a release of latent heat and to a warming of the warm air above the condensation level. Consequently, the thermal contrast between the warm and the cold air increases. This effect is even amplified if precipitation falls through the frontal surface into the cold air beneath. Here it evaporates to some extent and cools the cold air as long as the cold air is undersaturated. Depending on the initial vertical profiles of temperature and relative humidity the release of latent heat may stabilize the air below the cloud level, but may destabilize it above. In case of conditional instability even static instability may occur after air is lifted and condensation takes place. Evaporative cooling, instead, stabilizes the air above the evaporation layer, but destabilizes it below.

The situation becomes more complicated if also freezing and melting are considered. Although the diabatic heat exchange belonging to these processes is less effective compared to that connected with condensation and evaporation, additional modifications of stratification and cross-frontal temperature contrast are the consequence. Closely beneath the freezing level air might be cooled by melting snow. Its impact on the stratification depends much on the respective height of this level and its relative position to the frontal surface.

\subsection{Two-Dimensional Simulations}

The variety of possible effects of diabatic processes on cold fronts exceeds the practicability of a numerical study. Hence, one has to renounce with a complete survey of conceivable combinations of warm air and cold air stratifications, humidity profiles, cross-frontal temperature differences, and other aspects.

This study is limited to a distinct selection of parameters describing the environment of a moving cold front. These parameters have been choosen not only to represent a possible realistic situation, but also to achieve clear effects due to orography and latent heat processes. Therefore, they fulfill the following conditions:

- The stratification of both, cold and warm air is moderately stable.

- The warm air is moist enough to allow the development of clouds and precipitation.

- The cold air is dry enough to enable the precipitation to evaporate partly.

- The cross-frontal temperature contrast is large enough to make the front clearly identifiable.

- Both, cross-frontal temperature contrast and cross-frontal component of the initial geostrophic wind, allow an evident influence of the orography on the movement of the front.

The initial conditions are common to all model simulations throughout this study. Figure 1 displays the vertical initial profiles of potential tem-

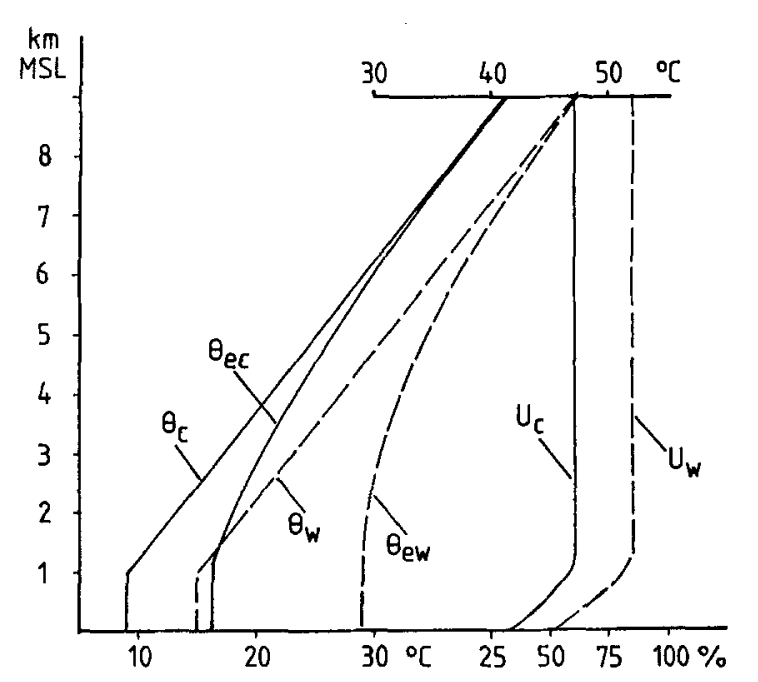

Fig. 1. Vertical profiles of potential temperature $(\Theta)$, equivalent-potential temperature $\left(\Theta_{e}\right)$, and relative humidity $(U)$ characterizing the initial and boundary state of the cold (index $c$ ) and warm (index $w$ ) air mass separated by the front 

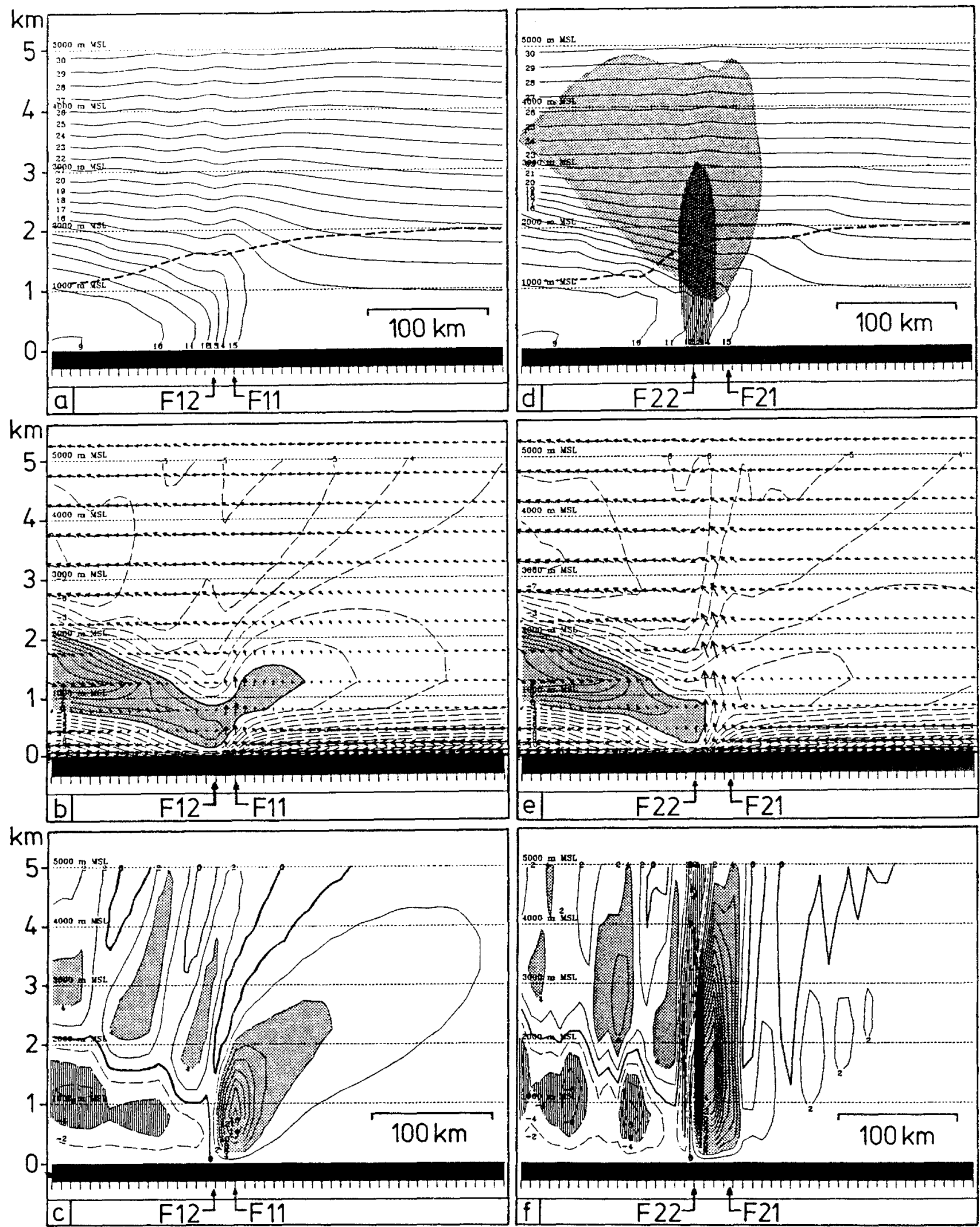

Fig. 2. Vertical cross-sections of the results of two-dimensional runs 2 D-1 (left-hand plates a, b, c) and 2 D-2 (right-hand plates $\mathrm{d}, \mathrm{e}, \mathrm{f})$ after 5 hours of simulation. Plates a and $\mathrm{d}$ show the potential temperature $\left(\Theta\right.$, isoline lables in ${ }^{\circ} \mathrm{C}$, contour interval $1 \mathrm{~K})$, cloud particle content $\left(q_{c}+q_{i} \geqslant 0.05 \mathrm{~g} / \mathrm{kg}\right.$ stippled) and precipitation content $\left(q_{R}+q_{S} \geqslant 0.01 \mathrm{~g} / \mathrm{kg}\right.$ vertically hatched). The dashed line indicates the freezing level. Plates $b$ and e illustrate the relative velocity component of the wind $\left(u-c_{F}\right)$ towards (stippled) or away from the front and the wind vectors $(u, w)$. Plates $c$ and $f$ show the vertical velocity component $(w)$. Upward motions $w \geqslant 4 \mathrm{~cm} / \mathrm{s}$ are stippled, downward motions $w \leqslant-4 \mathrm{~cm} / \mathrm{s}$ are vertically hatched. Positions marked by F 11 etc. are explained in text 
perature and relative humidity for both, cold and warm air mass. Notice the neutral stratification below $z=1000 \mathrm{~m}$ MSL. It was introduced to reduce the time needed to achieve a quasi-stationary boundary layer. To avoid conditional instability the relative humidity was reduced in this layer such as to guarantee a positive vertical gradient of the equivalent-potential tempertures, i.e. $\partial \Theta_{e}$, warm $/$ $\partial z \geqslant 0$ and $\partial \Theta_{e, \text { cold }} / \partial z \geqslant 0$.

The initial geostrophic wind in the warm air has a speed of $20 \mathrm{~m} / \mathrm{s}$ and an angle of $60^{\circ}$ to the $x$-axis, i.e. $u_{g}=10.0 \mathrm{~m} / \mathrm{s}, v_{g}=17.3 \mathrm{~m} / \mathrm{s}$.

Two two-dimensional ( $x-z-$ plane) runs have been carried out to demonstrate basic effects of moisture processes on a cold front moving over flat terrain. The numerical grid provides a horizontal resolution of $\Delta x=8 \mathrm{~km}$ and uses 20 levels up to a height of $9 \mathrm{~km}$ with a vertical spacing varying from $\Delta z^{*}=0.005(\Delta z \approx 50 \mathrm{~m})$ near the ground to $\Delta z^{*}=0.1(\Delta z \approx 1000 \mathrm{~m})$ near the top. The runs only differ from each other by whether cloud-physical processes are turned off (run 2D1) or on (run 2D-2), cf. Table 1.

The results are presented after five hours of simulation when precipitation has already developed in 2D-2. The position of the surface front is marked by two arrows (F 11, F 12 for 2 D-1 and F 21, F 22 for 2D-2) in Fig. 2. The first arrow (F 11 or F 21) indicates the position of the onset of cold air advection, the second one (F 12 or F 22) points to the position of maximum surface wind speed. Both front criteria are separated by $20 \mathrm{~km}$ in the dry case und $32 \mathrm{~km}$ in the wet case. From the positions $\mathrm{F} 11$ and $\mathrm{F} 21$ at $t=3 \mathrm{~h}$ and $t=6 \mathrm{~h}$ frontal speeds are deduced. They amount to $c_{F}=12.9 \mathrm{~m} / \mathrm{s}$ for $2 \mathrm{D}-1$ and $c_{F}=14.2 \mathrm{~m} / \mathrm{s}$ for $2 \mathrm{D}-2$. Hence, the front was accelerated by $10 \%$ due to moisture processes.

A brief discussion of selected fields of model parameters will elucidate relevant dynamic processes which have led to this result. Figure 3 offers a clear view of the effects. It shows the potential temperature difference and the difference vectors ( $u$ - and $w$-component) between both runs ( $2 \mathrm{D}-2$ -2 D-1) after 5 hours of simulation respectively. Evidently, the moisture processes heated the model atmosphere by up to $1.5 \mathrm{~K}$ between altitudes of 1500 to $4000 \mathrm{~m}$ near and behind the surface front position. On the other hand they cooled it by up to $2.5 \mathrm{~K}$ in lower levels. The location of warmed and cooled portions can be explained by

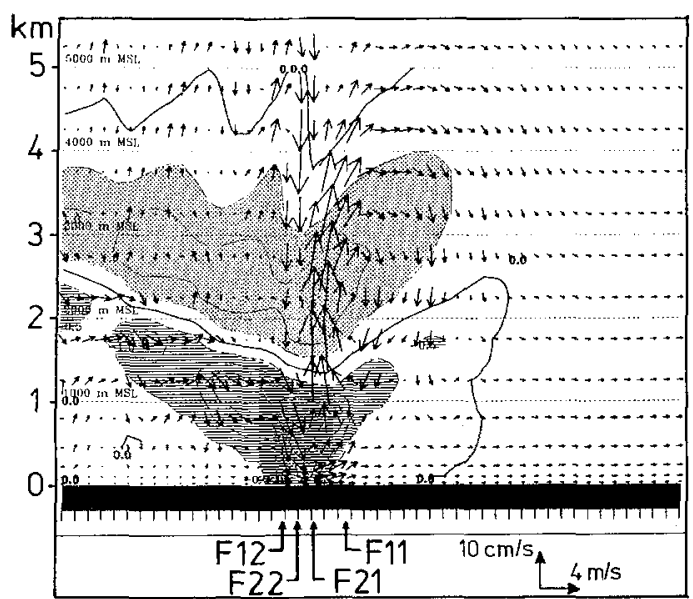

Fig. 3. The vertical cross-section (same as in Fig. 2) shows potential temperature difference and difference vectors $(u, w)$ of runs 2D-2-2D-1 after 5 hours of simulations. The stippled area indicates warming (more than $0.5 \mathrm{~K}$ ) due to the release of latent heat. The horizontally hatched area marks cooling (more than $0.5 \mathrm{~K}$ ) due to melting and evaporation. The positions F 11 etc. correspond to those in Fig. 2

the positions of frontal clouds, precipitation and freezing level as shown in Fig. 2 d. Notice that the temperature difference is not an indicator of the momentary gain or loss of latent heat. It is rather a result of past latent-heat exchanges and advection. Hence, the imbalance of warming and cooling is partly due to the faster advance of the front and the cold air in 2D-2. The intensity of precipitation is rather weak. It amounts to $1.2 \mathrm{~mm} / \mathrm{h}$ near the cloud base but reduces to $0.4 \mathrm{~mm} / \mathrm{h}$ at the ground as the falling rain partly evaporates in the undersaturated air.

The areas of cooling and warming are closely related to a speed up of the air flow compared to the dry situation. The moisture processes produce a strong upward acceleration in the area of greatest warming. Near the ground a strong foreward acceleration is generated at the leading edge of the air cooled by evaporating precipitation. The consequent divergence at its rear side leads to a narrow column of descending air just behind the updraft region (see Fig. 2 f).

In the upwind direction of the surface front the warming of the warm air aloft and the cooling of the cold air beneath increase the thermal contrast across the inclined frontal surface. This leads to an acceleration of the cold air. The relative crossfrontal flow $u-c_{F}$ is displayed in Figs. $2 \mathrm{~b}$ and $2 \mathrm{e}$ for both runs. The maximum values of $u-c_{F}$ 
do not differ much. Hence, the increase of $u$ coincides with an increase of $c_{F}$ by almost the same amount.

Another major difference between the two runs appear in the fields of vertical velocity (Figs. 2e and $2 \mathrm{f}$ ). While in the dry case the axes of upward motions are evidently tilted in downwind direction, they are almost upright in the wet case. A cellular structure of upward motion developed in the warm air behind the front. Its wave length does not depend on the grid spacing as test runs have shown. The wave length is not influenced much by the moisture processes, but the wave amplitudes are significantly enhenced by a factor of about 1.5 .

\section{Numerical Simulations of Cold Fronts over Realistic Orography}

\subsection{Diagnostic Tools for Evaluating the Model Output}

The tremendous amount of data which are obtained from numerical simulations demands a careful selection of relevant parameters on certain spatial slices at distinct times. Moreover, it is necessary to derive secondary parameters, which show atmospheric situations and developments more clearly and more precisely than primary quantities like $u, v, w, \Theta$, p, etc. Specifically, one must extract appropriate tokens from the original model output in order to trace non-material properties or phenomena like fronts.

An important physical parameter for the identification of air masses is the equivalent-potential temperature $\Theta_{e}$. Since it is conserved during condensation and evaporation, it is a better marker of an air mass than the potential temperature, which is invariant only in a dry atmosphere. The equivalent-potential temperature is calculated by

$\Theta_{e}=\frac{1}{\pi} \cdot\left(T+\frac{\ell_{c} q_{v}}{c_{p d}}\right)=\Theta+\frac{\ell_{c} q_{v}}{\pi c_{p d}}$

A useful tool for an objective analysis of front lines in numerical models is the so-called "thermal front parameter", which was introduced by Renard and Clarke (1965) and used, for instance, by Huber-Pock and Kress (1989). In this study we distinguish the thermal front parameter TFP, deduced from the potential temperature field, and the equivalent thermal front parameter $(E F P)$, deduced from the equivalent-potential temperature field. The TFP is given by

$T F P=-\nabla|\nabla \Theta| \cdot \frac{\nabla \Theta}{|\nabla \Theta|}$

with $\nabla$ as the two-dimensional nabla operator in a terrain following plane. The EFP is defined analogously with $\Theta_{e}$ replacing $\Theta$. According to this definition, the maximum lines of $T F P$ or $E F P$ identify fronts at the warm-air boundary of highgradient zones of $\Theta$ or $\Theta_{e}$. Maximum lines of TFP and $E F P$ do not match necessarily. In such a case the TFP represents a "dynamic" front line, since the potential temperature is closer related to the pressure field than the equivalent-potential temperature. The $E F P$ is rather an identifier of air mass boundaries. TFP and EFP are necessary criteria of a front on a horizontal plane. Besides them other criteria like wind shifts, confluences, vorticity maxima, pressure troughs, etc. identify a front.

The model output was organized as follows:

Horizontal and vertical cross-sections as well as terrain following arrays of various primary and secondary parameters have been stored every 90 minutes. The available material allows the construction of isochrones and difference fields or difference vectors in order to visualize temporal evolutions and spatial variations of different runs.

Additionally, vertical profiles of model parameters have been preserved at selected locations at each time step, so that time-height diagrams can be constructed. Although the model atmosphere extends to $9 \mathrm{~km}$ MSL, vertical cross-sections and time-height diagrams are restricted to altitudes below $5 \mathrm{~km} \mathrm{MSL}$, i.e. to altitudes clearly below the damping layer (see Section 2.3).

\subsection{Definition of a Model Domain Covering the Alpine Region}

The grid domain is defined on a geographic net with constant mesh widths $\Delta \lambda$ and $\Delta \varphi$. For this study the size of the model domain was chosen to include the entire Alps together with a marginal strip of about $200 \mathrm{~km}$ width to each side of the mountains. The grid domain is resolved by $40 \times 40$ meshes with a spacing of $\Delta \lambda=6.5 \mathrm{mrad}$ and $\Delta \varphi=3.3 \mathrm{mrad}$. This corresponds to a metric 


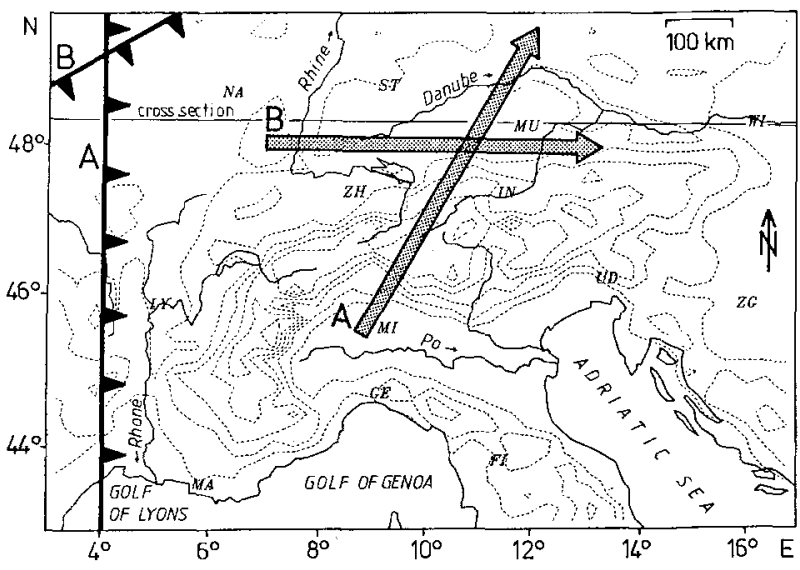

Fig. 4. Map of the model domain showing an area of approximately $1100 \times 750 \mathrm{~km}^{2}$ covered by $38 \times 38$ meshs. The dashed isolines represent the orography (terrain elevation above MSL, contour interval $400 \mathrm{~m}$ ) as used in the simulations, "A" and "B" mark the initial front orientations and the initial large-scale wind direction for cases A and B. Twoletter abbreviations stand for places: Nancy (NA), Stuttgart (ST), München (MU), Wien (WI), Zürich (ZH), Innsbruck (IN), Lyon (LY), Milano (MI), Udine (UD), Zagreb (ZG), Marseille (MA), Genova (GE), and Firenze (FI). The line "cross-section" refers to Fig. 7 and 9

grid distance of $\Delta x=26.8, \ldots, 30.8 \mathrm{~km}$ and $\Delta y=20.8 \mathrm{~km}$. The grid values of the terrain elevation represent the Alpine mountain range fairly well, but they are too coarse as to allow the resolution of Alpine valleys. The orographic data are taken from a digital geographic data base as mean values of the grid meshes. A map of the model domain is presented in Fig. 4. The vertical discretization into 20 levels is identical to that described in Section 3.2 .

\subsection{Aims and Strategy of Real-Orography Simulations}

Despite of the great variety of frontal events near the Alps this study is restricted to two main types of cold fronts, distinguished by their synopticscale environment. Using the terminology of Hoinka (1985) we concentrate on the "southwesterly type" and the "westerly type", depending on the direction of the upper tropospheric synoptic-scale air flow. In the numerical simulations the southwesterly and the westerly type are represented by initial geostrophic wind directions in the warm air of $210^{\circ}$ and $270^{\circ}$, respectively. In both cases the according front lines form an angle of $60^{\circ}$ to the air flow direction, i.e. the front orientations are $270^{\circ}$ for the southwesterly type and $330^{\circ}$ for the westerly type. By the term "front orientation" the direction of the front-normal vector is meant. The initial geostrophic wind speed in the warm air was set to $20 \mathrm{~m} / \mathrm{s}$. Hence, the crossfrontal geostrophic wind component amounts to $10 \mathrm{~m} / \mathrm{s}$ in either case.

The inital position of the surface front lines and the initial direction of the geostrophic wind in the pre-frontal warm air are plotted in Fig. 4. From now on the two configurations are addressed as "A" and " $B$ ",

Due to the WSW-ENE-orientation of the Alpine ridge the southwesterly type is connected with pre-frontal foehn north of the Alps. As Hoinka (1985) pointed out the pre-frontal foehn air mass is very dry within the lowest $4 \mathrm{~km}$ of the troposphere and consequently does not support the formation of clouds and precipitation in the pre-frontal area. At the rear side of the front the wind shifts to westerly directions and the cold air mass is blocked by the orography. The southwesterly front type has no or little precipitation in the prefrontal area but an intensified one in the postfrontal area. The westerly type is not associated with foehn north of the Alpine ridge. There is, in contrary, a slight tendency of blocking of the prefrontal warm air. Behind the front the wind usually turns to northwest and the blocking is even enhanced. Consequently pre-frontal precipitation is likely to occur and the total amount of precipitation north of the Alps is usually higher than for the southwesterly type.

The aim of the three-dimensional numerical simulations is a detailed inspection of both types of fronts, allowing answers to the following questions:

- How differently do the fronts appear when they approach the Alps from different directions?

- How differently do clouds and precipitation develop near the Alps?

- What consequences has the respective distribution of clouds and precipitation to the behaviour of the fronts as they approach the Alps?

All together six three-dimensional model simulations have been carried out to give the desired answers. They have the following systematic (Table 1):

Two basic runs simulate the development of both front types A and B, namely the southwest- 
erly type ( $3 \mathrm{D}-\mathrm{A} 0$ ) and the westerly type ( $3 \mathrm{D}-\mathrm{B} 0$ ), taking into account the Alpine orography and latent heat effects. These runs enable comparisons between the two fronts.

Two further runs (3 D-A 1 and 3 D-B 1) simulate the same situations but with a "cut-off" orography where the maximal terrain elevation is limited to $500 \mathrm{~m}$ MSL. The Alps then reduce to a plateau which joins the northern Alpine foreland without a step. A comparison of $3 \mathrm{D}$-A 1 with $3 \mathrm{D}$ $\mathrm{A} 0$ and of $3 \mathrm{D}-\mathrm{B} 1$ with $3 \mathrm{D}-\mathrm{B} 0$ clarifies the role of orography on the frontal propagation and on the development of clouds and precipitation.

The last two runs, 3 D-A 2 and 3 D-B 2 , simulate the fronts with full orography, but without any latent heat exchange. These runs, when compared with $3 \mathrm{D}-\mathrm{A} 0$ and $3 \mathrm{D}-\mathrm{B} 0$, serve to explore the role of latent heat effects with respect to the movement of fronts and their retardation or acceleration by the Alps. In order to guarantee comparability all model parameters are equal in both cases besides the direction of the initial geostrophic flow and the front orientation. The initial vertical temperature and humidity profiles are illustrated in Fig. 1.

All 3 D-simulations extend over a period of 18 hours. During this time the simulated fronts completely cross the northern Alpine foreland in all six runs.

\subsection{General Description of the Results}

In order to give an overview, the temporal development of the two fronts as simulated in runs $3 \mathrm{D}$ A 0 and $3 \mathrm{D}-\mathrm{B} 0$ is presented by three-hourly synoptic surface weather charts showing surface front lines, sea level pressure, surface winds, and pre- cipitation areas. To define the surface front positions the conventional synoptic method of surface front analysis was used. The surface front lines are connected with wind shifts, horizontal temperature gradients, changes in humidity, and they lie in a pressure through.

Later on, in Section 4.5, a more detailed description will be given. Additional parameters, as well as vertical cross-sections are used to take advantage of the three-dimensional simulations, and to explain principal effects rather than to just describe the results.

\subsubsection{Case A: A Cold Front with Pre-Frontal Foehn}

The "synthetic" weather maps (Fig. 5) visualize the numerical realization of the frontal development under the prescribed assumptions. They show a couple of characteristic features which are known from the variety of "natural" developments with large-scale wind directions and front orientations similar to those of case $\mathrm{A}$ :

- Pre-frontal foehn generates a low pressure trough north of the Alps.

- A convergence line forms in the area of lowest pressure in the northern Alpine foreland. It separates easterly to southerly flow in the east from southwesterly flow in the west.

- The surface front line accelerates north of the Alps until it has caught up to preceding convergence line by $t=+15 \mathrm{~h}$. Afterwards it slows down remarkably.

- A tongue of high pressure expands behind the front along the northern edge of the Alps.

- The easterly flow over the Po River plain is replaced by westerly winds as soon as the front line passes.

Table 1

\begin{tabular}{lllll}
\hline Run number & Orography & Latent heat effects & Initial front orientation & Initial large-scale wind direction \\
\hline 2 D-1 & flat & no & $270^{\circ}$ & $210^{\circ}$ \\
2D-2 & flat & yes & $270^{\circ}$ & $210^{\circ}$ \\
\hline 3 D-A 0 & full & yes & $270^{\circ}$ & $210^{\circ}$ \\
3D-A 1 & cut-off & yes & $270^{\circ}$ & $210^{\circ}$ \\
3D-A 2 & full & no & $270^{\circ}$ & $210^{\circ}$ \\
3D-B 0 & full & yes & $330^{\circ}$ & $270^{\circ}$ \\
3D-B 1 & cut-off & yes & $330^{\circ}$ & $270^{\circ}$ \\
3D-B 2 & full & no & $330^{\circ}$ & $270^{\circ}$ \\
\hline
\end{tabular}



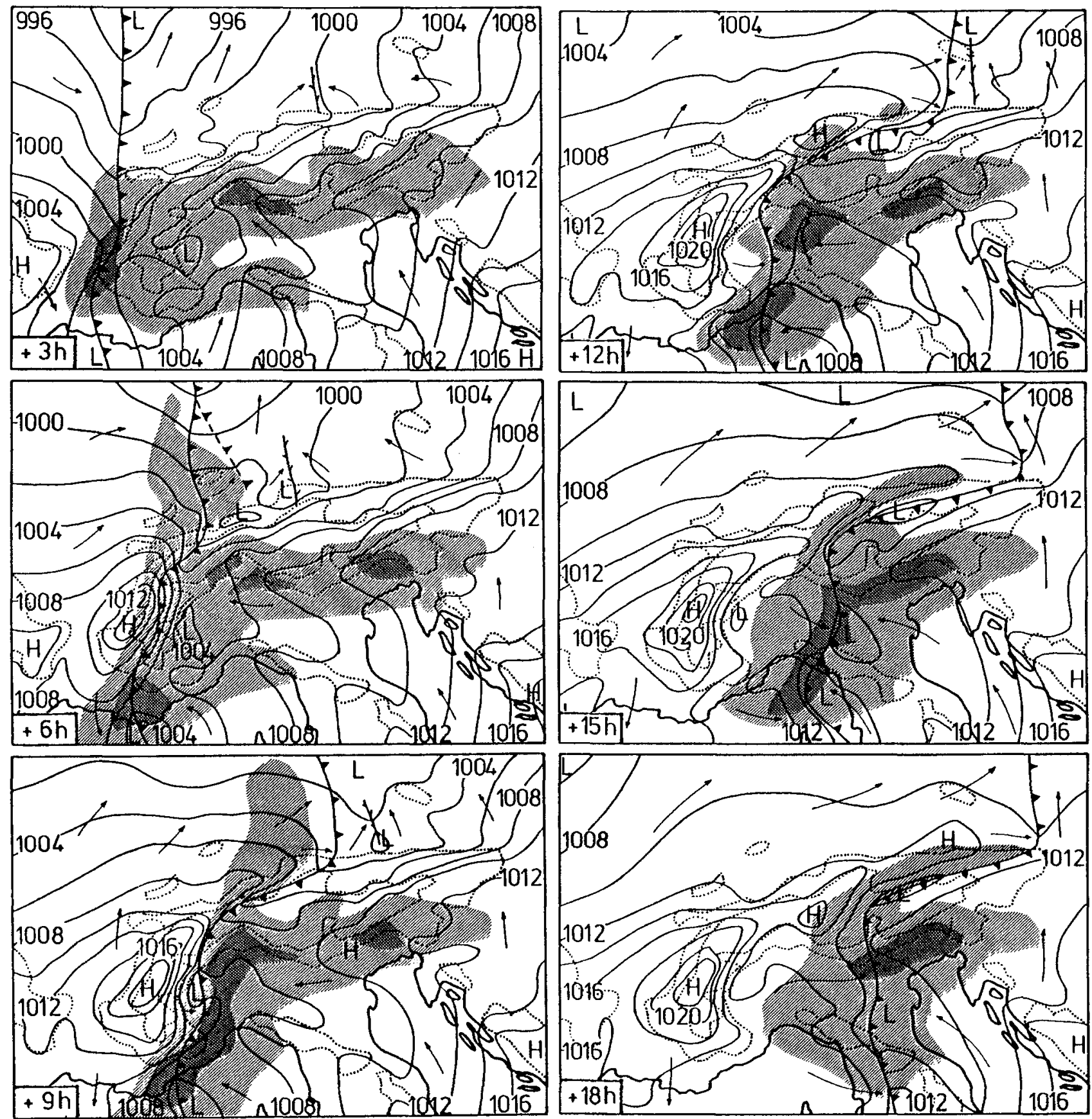

Fig. 5. Synthetic three-hourly surface weather maps illustrating the results of $3 \mathrm{D}$-A 0 . The maps show isobares (hPa) of pressure reduced to MSL, positions of fronts and convergence lines, wind directions, and precipitation intensity (threshold values are 0.5 and $5 \mathrm{~mm} / \mathrm{h}$ ). The dotted lines represent terrain elevations of 800 and $1600 \mathrm{~m} \mathrm{MSL}$, respectively

Enhanced precipitation forms in the damming areas at the western Alps and along the southern Alpine rim.

- Light precipitation forms along the northern part of the front. It is left behind the front at $t=+9 \mathrm{~h}$ and disappears as dry foehn air is encountered.
Precipitation starts again when cold air is forced to rise along the northern Alpine rim after $t=+12 \mathrm{~h}$, but a foehn gap without precipitation remains north of the Alpine main ridge between $t=+12 \mathrm{~h}$ and $t=+18 \mathrm{~h}$.

Two critical aspects have to be mentioned: Firstly, due to the near inflow boundary unreal- 

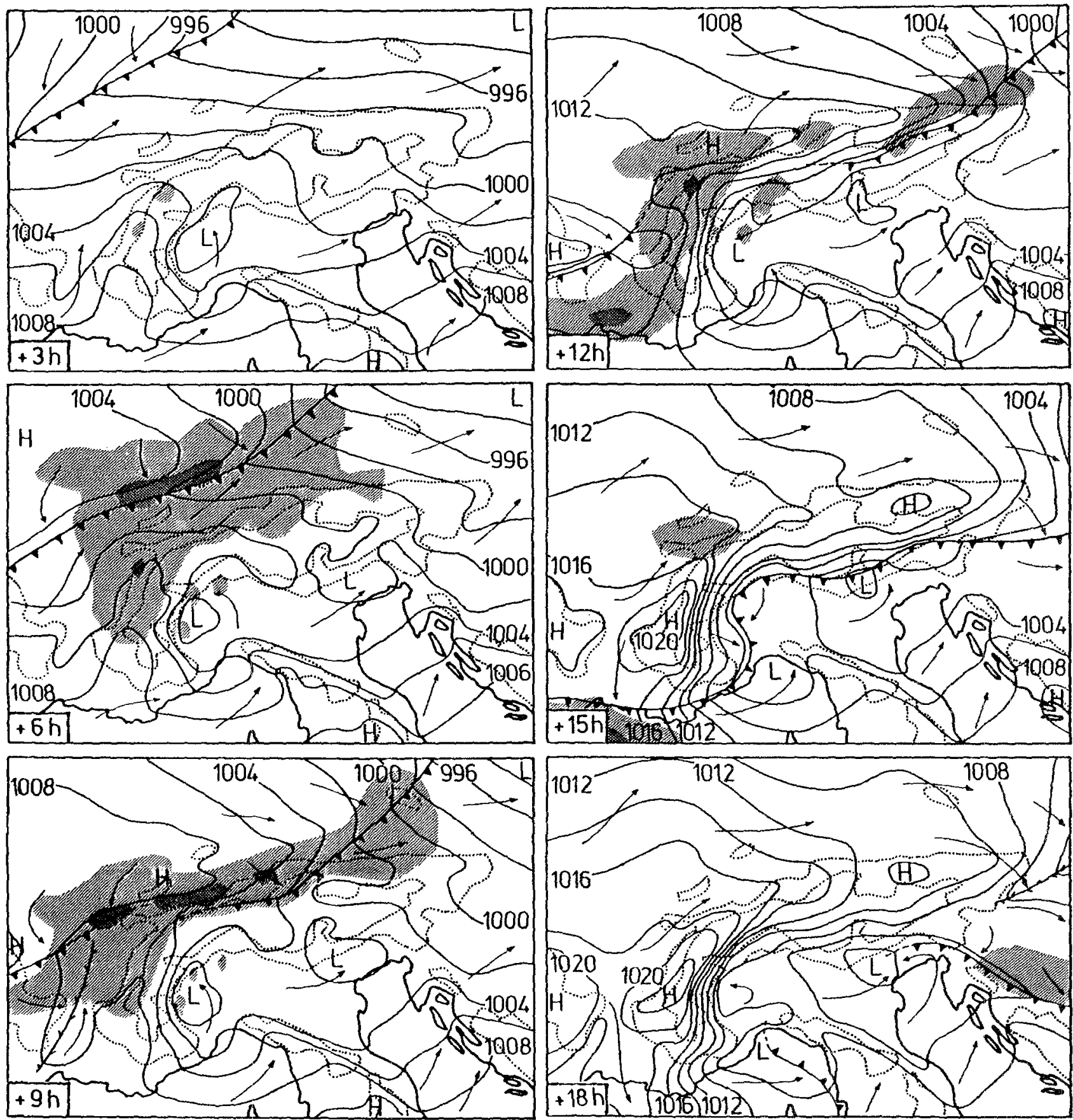

Fig. 6. Synthetic three-hourly surface weather maps as shown in Fig. 5 but illustrating the results of $3 \mathrm{D}-\mathrm{B} 0$

istic high wind speeds (up to $25 \mathrm{~m} / \mathrm{s}$ ) are generated in the lee of the Central Massif (France) which push the cold air against the western Alps. A strong pressure rise is caused there and the cold air is lifted across the Alps. Thus, it enters the Po River plain sooner as one usually observes.

Secondly, the precipitation rate amounts up to $10 \mathrm{~mm} / \mathrm{h}$ at distinct locations at the southern Al- pine rim. Due to its long duration the precipitation accumulates to $50 \mathrm{~mm}$, partly even to $80 \mathrm{~mm}$ within 18 hours. Although such high values are observed in northern Italy in extreme cases, they are not characteristic for weather situations which are similar to the synthetic case. One reason might be the prescribed high humidity in the warm air mass. 
4.4.2 Case B: A Cold Front with Slight Orographic Blocking

In case B typical features developed which are frequently observed when cold fronts approach the Alps from northwest. They are illustrated in Fig. 6 and are listed below:

- The front propagates within a sharp pressure trough and is connected with a distinct wind shift from southwest to northwest over the northern Alpine foreland.

- Pressure minima form in the lee of the Alps over the Po River plain. A recirculation is generated over the western part of the Po River plain.

- A precipitation area forms along the front and in the blocking area along the mountains. High precipitation rates $(>2.5 \mathrm{~mm} / \mathrm{h})$ concentrate close to the front line.

- The front is retarded at the Alps and therefore evidently distorted.

- The surface front crosses the Alps by $t=+15 \mathrm{~h}$ and is dissolved over the Po River plain till $t=+18 \mathrm{~h}$.

- The front accelerates east of the Alps and quickly turns southward to Yugoslavia.

- The tongue of high pressure expanding eastward behind the front extends farther into the northern Alpine foreland than in case A.

The precipitation north of the Alps ceases shortly after the front penetrates into the mountains. This is caused by the prescribed dryness of the cold air mass $(U \leqslant 60 \%)$ and by the almost mountain parallel air flow that re-establishes at the rear side of the front.

\subsection{Detailed Inspection of the Simulated Fronts}

The model simulations offer a variety of specific information that is not available from observations. Some of it is used here to investigate the impact of orography and latent heat effects on the fronts in the vicinity of the Alps and to enable a deeper insight into the meteorological structures connected with the frontal passage. The following discussion is restricted to phenomena occurring over the northen part of the Alps and the adjacent foreland, i.e. within the inner experimental area of GFE 87.

\subsubsection{Influence of Orography and Latent Heat Effects}

The role of the Alpine orography and latent heat effects will be explained in detail for case $A$ where the effects seem to be more pronounced than in case B. The influence of the Alps was excluded in $3 \mathrm{D}-\mathrm{A} 1$ where the terrain elevation was limited to $500 \mathrm{~m}$ MSL. The subtraction of parameter fields resulting from this run from the corresponding fields resulting from the complete run $3 \mathrm{D}$-A 0 yields difference fields which are used to elucidate the mountain effects. Figure 7 a shows a west-east cross-section along a line indicated in Fig. 4 at $t=+9 \mathrm{~h}$. At this time the front has apparently encountered an influence of the Alpine orography. The most prominent feature is the positive difference of potential temperature in the pre-frontal air. The descending motion of the northern Alpine foehn warms the lower troposphere by up to $5 \mathrm{~K}$ compared to $3 \mathrm{D}-\mathrm{A} 1$ where the absence of the Alps prevents a foehn flow. The warming has two consequences: It increases the temperature contrast between the pre-frontal warm air and the postfrontal cold air, and it reduces the pressure over the northern Alpine foehn area. Both effects ac-
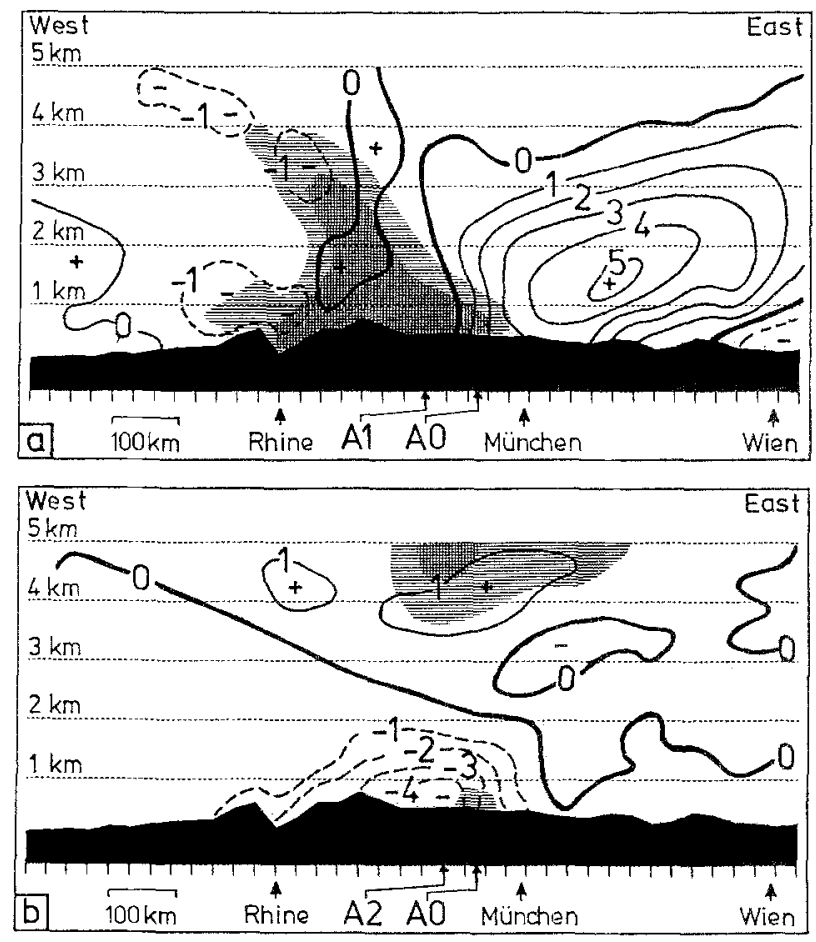

Fig. 7. Vertical west-east cross-section along the line shown in Fig. 4 (labeled "cross-section") displaying the differences of potential temperature $(\Theta$, isoline labels in $K)$ and westeast wind component ( $u$, stippled, threshold values 2 and $4 \mathrm{~m}$ / s) resulting from runs with full and with flat orography (Plate a: 3 D-A $0-3$ D-A 1) and from runs with and without latent heat effects (Plate b: 3 D-A 0-3D-A 2). Surface front positions of the respective runs as deduced from TFP are indicated by "A 0", "A I", and "A 2" 
celerate the post-frontal westerly flow by up to $8 \mathrm{~m} / \mathrm{s}$. As a consequence the cold front moves faster towards the east. This is in accordance with results of numerical studies by Egger (1989) who used a three-layer model of a cold front with prefrontal flow across an idealized mountain barrier. On the contrary to the present investigation, he did not remove the orography but reduced the static stability in order to prevent foehn. The front moved always faster in cases of pre-frontal foehn.

The effect of latent heat exchange is illustrated in Fig. $7 \mathrm{~b}$ by the fields of $\Theta$ and $u$ of $3 \mathrm{D}-\mathrm{A} 2$ subtracted from the corresponding fields of the complete run $3 \mathrm{D}-\mathrm{A} 0$. The vertical west-east crosssection corresponds with that shown in Fig. 7 a.

Similar to the difference field in Fig. 3 a cooling is caused by the evaporation of rain and the melting of snow in the lower $2 \mathrm{~km}$ of the atmosphere. In the cloud layer between 3 and $5 \mathrm{~km}$ MSL a warming appears which is somewhat weaker than the cooling below. Notice that cooled and warmed areas do not mark locations of actual evaporation/ melting or condensation/freezing. They are rather the product of latent heat exchange and advection since the time of initialization. Nevertheless, the result is similar to the orographic effect: The latent heat processes increase the temperature contrast between the two air masses and accelerate the $u$ component of the wind.

In summary, both influences, the presence of mountains and the thermodynamic action of water phase conversions, lead to an acceleration of the eastward propagation of the cold front north of the Alps. In combination, the temperature contrast increases by almost $10 \mathrm{~K}$ or $160 \%$ (at $1000 \mathrm{~m}$ MSL) due to both influences.

The horizontal map at $t=+9 \mathrm{~h}$ (Fig. 8) illustrates the complex structure of the fields of potential and equivalent-potential temperature north of the Alps. Figure 8 a exhibits a tongue of potentially warm foehnic air which extends from the Alps to the north. At its western side it is bounded by a zone of strong horizontal gradient connected with the front. The position of the maximum line of the thermal front parameter TFP (cf. Section 4.1 ) is indiated by cold front symbols. A further line of this kind extends from northern Yugoslavia across the Adriatic Sea to northern Italy. It is not connected with an actual front but represents the leading edge of air which was remarkably cooled by evaporating rain over the Po River plain south of the Alps. This line slowly moves southeastward against the air flow as can be deduced from maps at later times not shown here.

One obtaines quite another impression from the distribution of the equivalent-potential temperature in Fig. 8 b. This quantity is not affected by latent heat exchanges and therefore is an appropriate air mass qualifier. The EFP maximum line lags behind the TFP maximum line by about $120 \mathrm{~km}$ north of the Alps. Active weather (clouds and precipitation) is related more to the EFP maximum (marked by "F 1") than to the TFP maximum ("F 2"). However, the dynamic fields (pressure, wind) show the strongest gradients near "F 2". This can be seen from the vertical crosssections of $u$ and $v$ in Figs. $9 \mathrm{~b}$ and $9 \mathrm{c}$. In summary, the influences of orography and latent heat exchange complicate the structure of the cold front
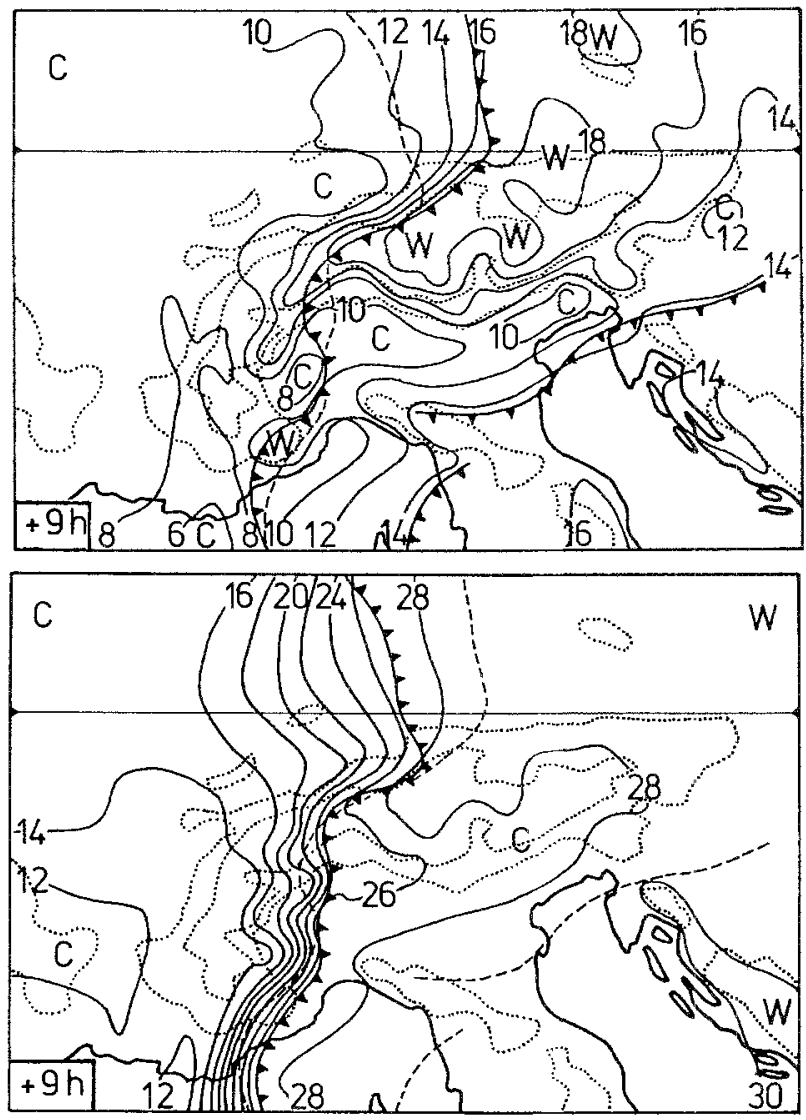

Fig. 8. Distribution (isoline labels in ${ }^{\circ} \mathrm{C}$ ) of the potential temperature (Plate a: $\Theta$ ) and the equivalent-potential temperature (Plate b: $\Theta_{e}$ ) at $50 \mathrm{~m}$ GND resulting from $3 \mathrm{D}-\mathrm{A} 0$ after 9 hours of simulation. The positions of the corresponding thermal front parameters (TFP and EFP) are presented by front symbols. The dashed lines serve to compare the positions of TFP and EFP 

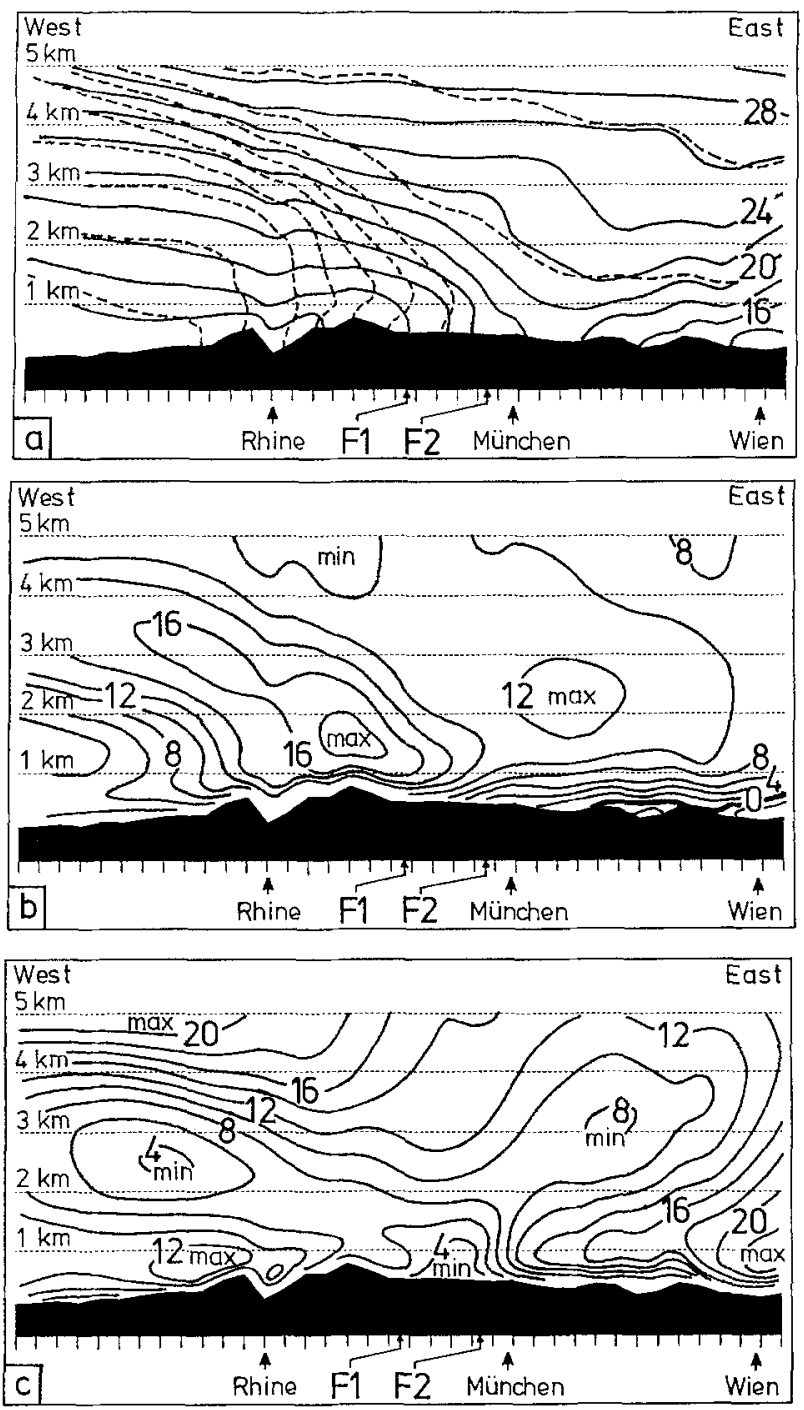

Fig. 9. Vertical west-east cross-section along the line shown in Fig. 8 presenting results of $3 \mathrm{D}-\mathrm{A} 0$ at $t=+9 \mathrm{~h}$. Plate a contains isolines (labels in ${ }^{\circ} \mathrm{C}$, contour interval $2 \mathrm{~K}$ ) of potential temperature $(\Theta$, full lines) and equivalent-potential temperature $\left(\Theta_{e}\right.$, dashed lines). Isolines (labels in $\left.\mathrm{m} / \mathrm{s}\right)$ of the west-east component $(u)$ and of the south-north component of wind $(v)$ are presented in plates $b$ and $c$. The positions marked by "F 1" and " $F 2$ " identify the EFP and TFP maximum near the surface, respectively

as it approaches the Alps. The model results suggest a splitting of the front into a dynamically active front line, represented by the $T F P$, and an air mass boundary represented by the EFP.

The propagation speeds of the surface front lines are analyzed using three-hourly isochrones. Their positions are defined by the maximum lines of TFP as defined in Section 4.1. The results of $3 \mathrm{D}-\mathrm{A} 0$ and $3 \mathrm{D}-\mathrm{A} 2$ (front from west) are plotted in Fig. 10 a, those of 3 D-B 0 (front from northwest) in Fig. 10 b.

Figure 10 a shows isochrones of the surface front line (maximum lines of $T F P$ ) of both simulations, the "dry" one (3 D-A 2) and the "moist" one ( $3 \mathrm{D}-\mathrm{A} 0)$. The front propagates evidently faster if water phase changes are turned on. By $t=+6 \mathrm{~h}$ prefrontal precipitation has cooled the warm air mass at lower layers leading to a secondary maximum line of TFP at the eastern boundary of the precipitation area. The front line of $3 \mathrm{D}-\mathrm{A} 0$ is well defined at $t=+9 \mathrm{~h}$ by its $T F P$ maximum and has speeded up from $12 \mathrm{~m} / \mathrm{s}$ to $27 \mathrm{~m} / \mathrm{s}$ if one measures the progress of the respective main TFP maximum line. The cold air mass, however, does not follow with the same speed as the propagation of the EFP maximum line indicates (cf. Fig. 8 b and 9 a). The greatest advance

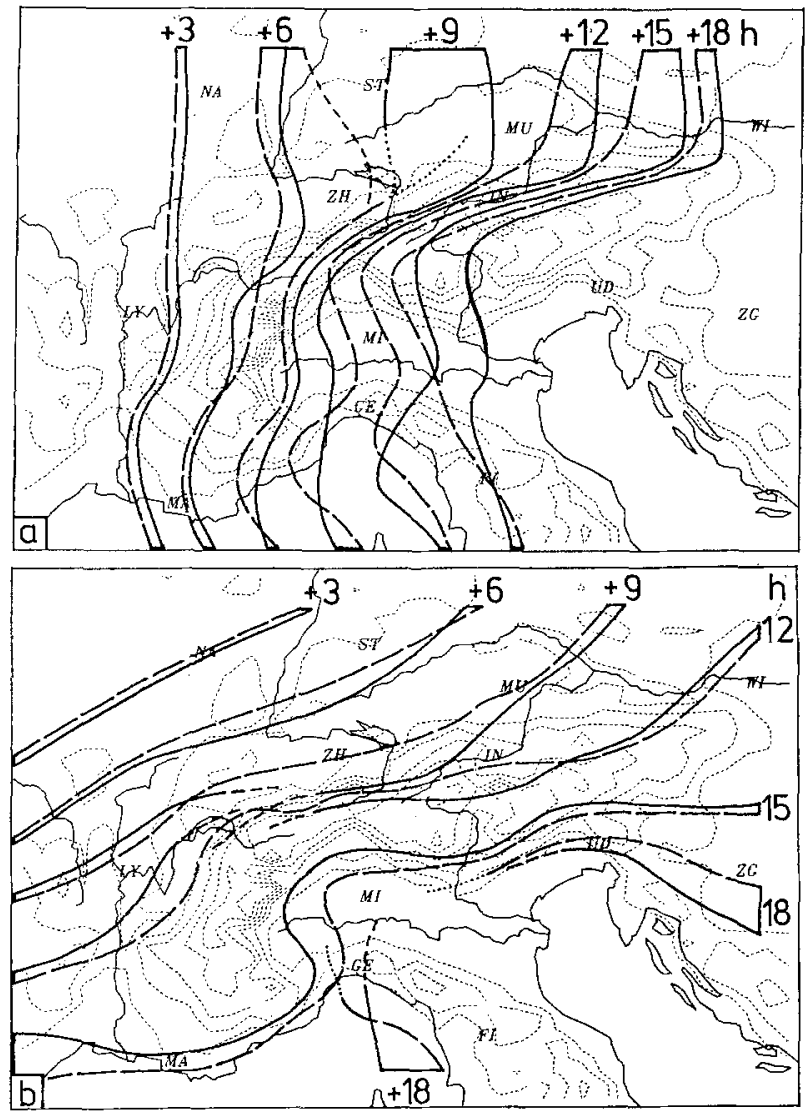

Fig. 10. Three-hourly isochrones of the surface fronts (maximum lines of $T F P$ ) of case A (plate a) and case B (plate b). The front positions of runs regarding latent heat conversions (3 D-A 0 ) are presented by full lines, those of runs neglecting latent heat conversions ( 3 D-A 2 and 3 D-B 2 ) are exhibited by longly dashed lines. Uncertain or ambiguous positions are plotted with shortly dashed or dotted lines, respectively 
is simulated between $t=+6 \mathrm{~h}$ and $t=+9 \mathrm{~h}$. During this time interval the orographic influence, i.e. the foehn effect, and the latent heat effect superimpose.

The results of $3 \mathrm{D}-\mathrm{A} 2$ (no latent heat exchange) are somewhat obscure respecting the TFP at $t=+9 \mathrm{~h}$. The tongue of foehnic warm air produces a separate TFP maximum line at its western boundary extending from Lake of Constance towards the northeast. During the next three hours this line becomes the main TFP maximum line while the original line, positioned shortly east of Stuttgart at $t=+9 \mathrm{~h}$, disappears. At $t=+12 \mathrm{~h}$ the maximum line of TFP are well defined again for both runs, $3 \mathrm{D}-\mathrm{A} 0$ and $3 \mathrm{D}-\mathrm{A} 2$. It travels with $12.2 \mathrm{~m} / \mathrm{s}$ (run $3 \mathrm{D}-\mathrm{A} 0$ with latent heat exchange) and $10.4 \mathrm{~m} / \mathrm{s}$ (run 3 D-A 2 without latent heat exchange), respectively. As the front approaches the eastern end of the Alps it slows down in either run, presumably because of the ceasing foehn effect.

The effect of latent heat exchange depends much on the location of precipitation relative to the surface front line. Only if rain falls into unsaturated air at the rear side of the front the accelerating effect is most pronounced as it is the
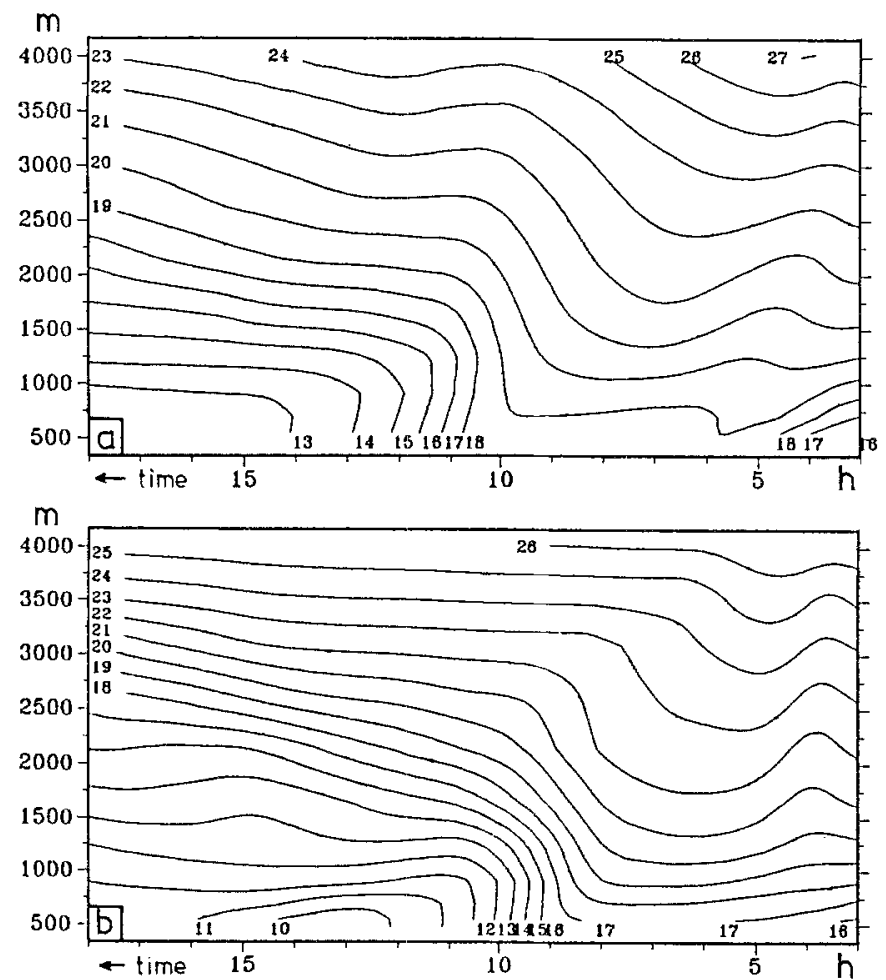

case for front $\mathrm{A}$. On the contrary, precipitation already forms ahead of front B. This is mainly due to an orographically forced lifting of the prefrontal air as the front gets closer to the Alps. In this case the cross-frontal temperature contrast is slightly decreased which leads to a deceleration of the front as it becomes evident after $t=+9 \mathrm{~h}$ in Fig. $10 \mathrm{~b}$.

\subsubsection{Appearance of the Frontal Passages as Simulated over München}

The different appearance of the frontal passages for cases $3 \mathrm{D}-\mathrm{A} 0,3 \mathrm{D}-\mathrm{A} 2,3 \mathrm{D}-\mathrm{B} 0$, and $3 \mathrm{D}-\mathrm{B} 2$ is visualized by time-height cross-sections of selected quantities over München. This location was choosen because of two reasons. Firstly, it is situated close enough to the mountains (approximately $60 \mathrm{~km}$ north of the Alpine baseline) to be within the range of the orographic influence. Secondly, München is a radiosonde station from which temporally condensed ascents during the GFE 87 's special observation periods were used to construct time-height cross-sections. They are published by Hoinka et al. (1988).
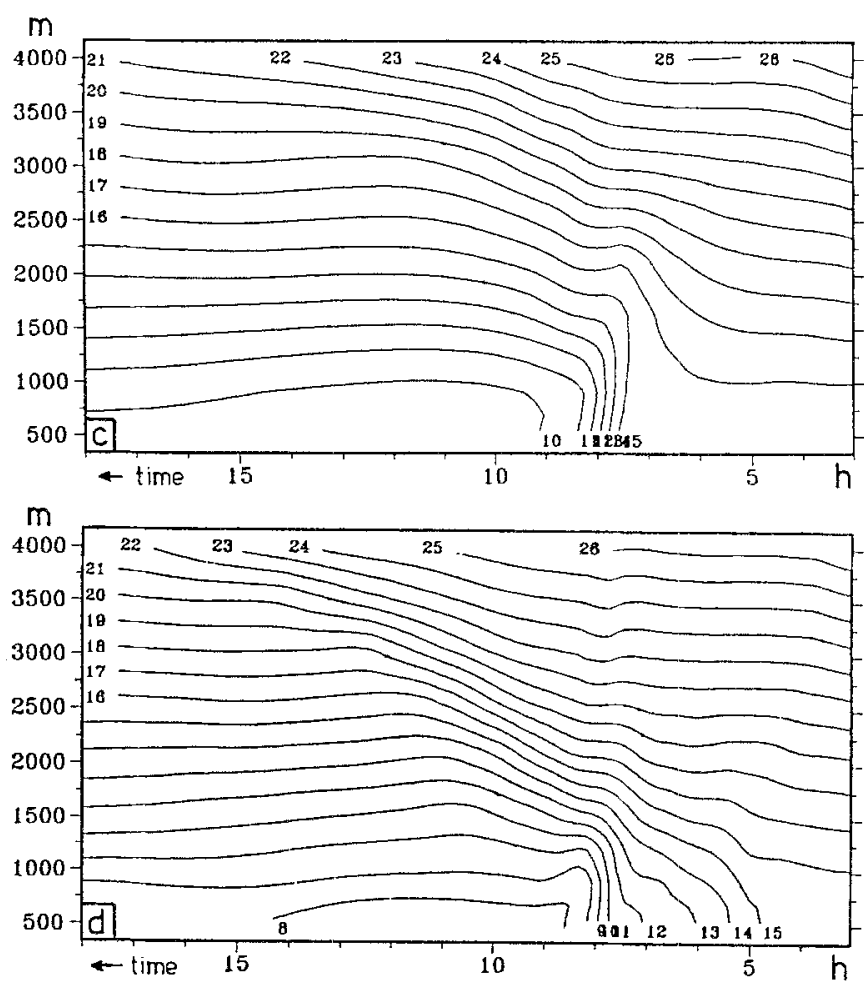

Fig. 11. Time-height diagrams overhead the location of München of 3 D-A 2 (plate a), 3 D-A 0 (plate b), 3 D-B 2 (plate c), and $3 \mathrm{D}-\mathrm{B} 0$ (plate $\mathrm{d}$ ), showing the isolines (labels in ${ }^{\circ} \mathrm{C}$, contour interval $1 \mathrm{~K}$ ) of potential temperature $(\Theta)$ 

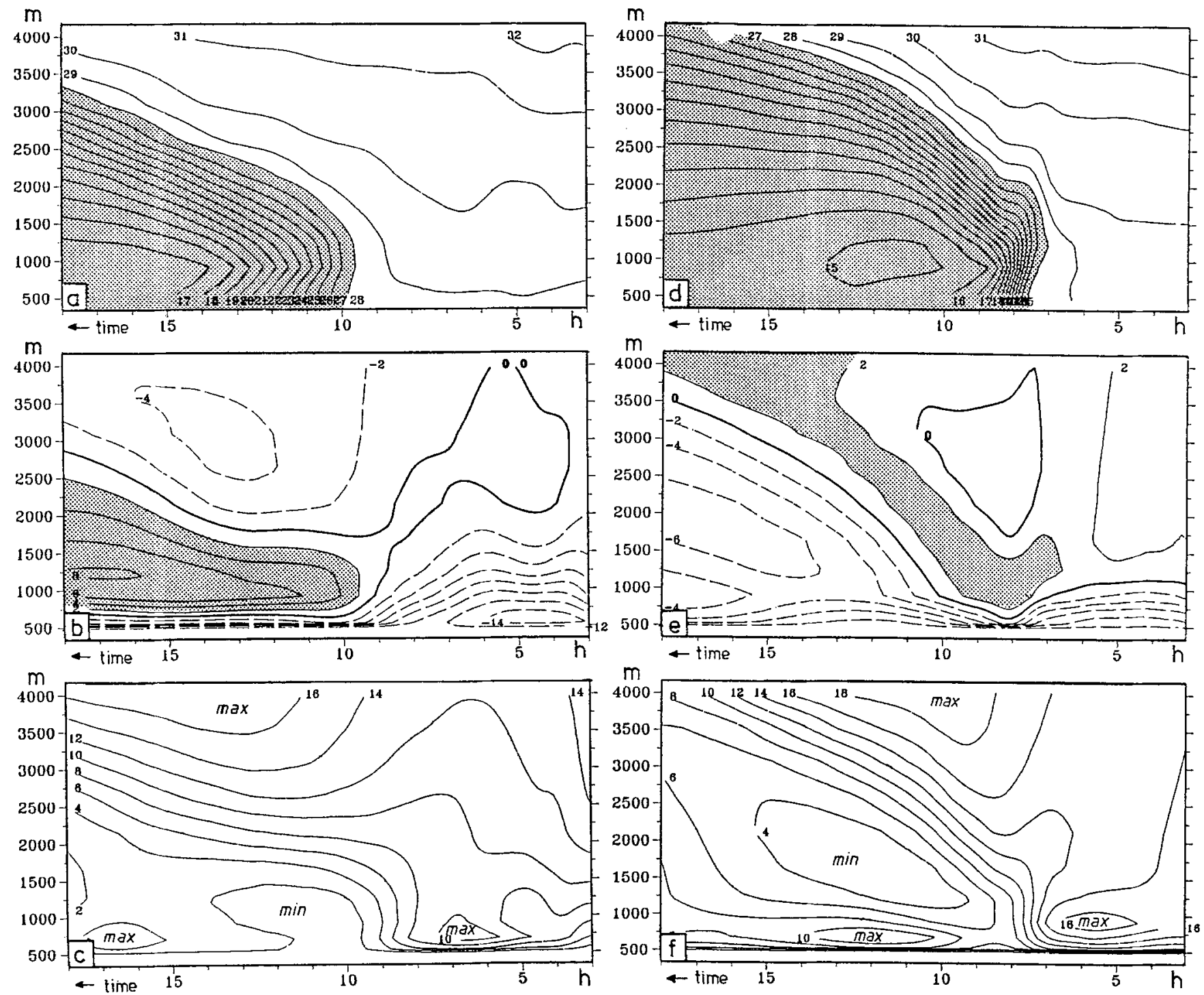

Fig. 12. Time-height diagrams overhead the location of München of 3 D-A 0 (left-hand plates a, b, c) and of 3 D-B 0 (righthand plates $\mathrm{d}, \mathrm{e}, \mathrm{f})$ showing the equivalent-potential temperature (Plates a and $\mathrm{d}: \Theta_{e}$, labels in ${ }^{\circ} \mathrm{C}$, contour interval $1 \mathrm{~K}$ ), the cross-frontal wind speed relative to the frontal movement (plates $\mathrm{b}$ and $\mathrm{e}: u_{F}-c_{F}$, contour interval $2 \mathrm{~m} / \mathrm{s}$, values $\geqslant+2 \mathrm{~m} / \mathrm{s}$ are stippled), and the front-parallel wind component (plates $\mathrm{c}$ and $\mathrm{f}: v_{F}$, contour interval $2 \mathrm{~m} / \mathrm{s}$ )

Figure 11 compares potential temperature timeheight cross-sections from simulations with different front orientation ( $3 \mathrm{D}-\mathrm{A} 0$ and $3 \mathrm{D}-\mathrm{A} 2$ vs. 3 D-B 0 and 3 D-B 2) and from "dry" and "moist" simulations ( $3 \mathrm{D}-\mathrm{A} 0$ and $3 \mathrm{D}-\mathrm{B} 0$ vs. $3 \mathrm{D}-\mathrm{A} 2$ and 3 D-B 2). The "dry" case with a westerly approach of the front and an initial flow from $210^{\circ}$ in the warm air mass (Fig. 11 a) clearly exhibits a foehnic warming as the isentropes sag before the surface front passes at $t=+10.5 \mathrm{~h}$. This is not the case if the front approaches from NNW with a westerly flow ahead (Fig. 11c). The foehn also increases the static stability within the boundary layer (below $1000 \mathrm{~m}$ MSL), but decreases it aloft. As the pre-frontal conditions appear to be different so do the fronts themself. Front B causes a faster temperature drop near the surface compared to Front A. At higher altitudes only a weak decrease of potential temperature is observed ahead of the surface front in $3 \mathrm{D}-\mathrm{B} 2$ whereas the termination of the foehn is accompanied with a more pronounced temperature decrease in $3 \mathrm{D}-\mathrm{A} 2$. The post-frontal temperature decrease expands to higher altitudes much faster for 3 D-B 2 (Fig. $11 \mathrm{c}$ ) 
than it does for $3 \mathrm{D}-\mathrm{A} 2$ where the cooling is restricted to a shallow layer below $3000 \mathrm{~m}$ MSL.

The situation is different if latent heat effects are permitted. At the surface, temperature decrease starts almost two hours earlier and the cooling rate is increases for Front A (Fig. 11 b). This is due to evaporation of post-frontal precipitation within the cold air mass. The time of the foehn termination, however, is not much influenced by the latent heat effects.

Front $\mathrm{B}$ is differently modified by diabatic heat exchanges as a comparison of Fig. $11 \mathrm{c}$ and $11 \mathrm{~d}$ shows. The partial evaporation of pre-frontal precipitation stabilizes and cools the warm air mass within the boundary layer. The main temperature drop, however, remains nearly unchanged at around $t=+8 \mathrm{~h}$. The release and loss of latent heat strengthens the temperature contrast and consequently increases the static stability within the inclined frontal layer.

Figure 12 shows the temporal development of further parameters resulting from $3 \mathrm{D}-\mathrm{A} 0$ and $3 \mathrm{D}-\mathrm{B} 0$, namely the equivalent-potential temperature $\left(\Theta_{e}\right)$, the cross-frontal wind compotent in a frame of reference moving with the front $\left(u_{F}-c_{F}\right)$, and the front-parallel wind component $\left(v_{F}\right)$. The values of $c_{F}$ were deduced from isochrones. They amount to $11.7 \mathrm{~m} / \mathrm{s}$ for case $A$ and $11.1 \mathrm{~m} / \mathrm{s}$ for case B. The diagrams of $\Theta_{e}$ (Fig. $12 \mathrm{a}$ and $12 \mathrm{~d}$ ) elucidate the air mass change over München. The cold air mass intrudes more abruptly and attains height faster in case B ( $3 \mathrm{D}-\mathrm{B} 0)$ than in case A (3 D-A 0). Also the dynamic fields look differently. Connected with Front A a strong post-frontal feeder flow is simulated within the entire depth of the cold air layer (Fig. 12b). On the contrary, Front B shows only a slight inflow from behind which concentrates closely beneath the inclined air mass boundary. The front-parallel wind component $\left(v_{F}\right)$ has a jet-like maximum below $1000 \mathrm{~m}$ MSL in either case. However, the speed of the low-level jet ahead of Front B exceeds that ahead of Front $\mathrm{A}$ by $80 \%$. An obvious explanation of these differences is the direction of the air flow relative to the orientation of the Alpine mountain range. In case $A$ the front-normal component is directed parallel to the mountains and therefore enhanced. The same is true for the front-parallel component in case $B$, which is, indeed, more pronounced than in case $A$.

\section{Conclusion}

The results show that processes which increase the temperature contrast across a front tend to accelerate the propagation of a cold front. Two such processes could be identified in this study. These are the foehn and latent heat conversions.

Foehn, generated by sufficiently stable stratified pre-frontal air crossing the Alps, warms the lower moiety of the troposphere by downward motion leeside the mountains within the pre-frontal warm air mass. Provided that the pre-frontal warm air is moist enough to allow condensation this air mass is warmed at altitudes where clouds appear. If precipitation forms behind the surface front-line and falls into the post-frontal cold air which is, moreover, dry enough to enable the precipitation partly to evaporate the sub-cloud layer of the cold air is additionally cooled. Hence, the temperature difference between both air masses increases under these presuppositions.

Such a configuration was simulated for case $A$ with a south-north orientated front and pre-frontal foehn-flow. In this case the front was accelerated north of the Alps by both foehn and latent heat conversions. Different model runs where either latent heat effects or foehn (as the consequence of the Alpine orography) were eliminated show that foehn contributes more to the acceleration than latent heat effects. The results of case $\mathrm{B}$, however, show that latent exchanges have not always an accelerating effect. Here, the cold front moves from the northwest and the pre-frontal air flows almost parallel to the mountain range with a weak component towards the Alps. Precipitation already forms ahead of the surface front line as the warm air is partly forced to rise at the northern Alpine rim. Since foehn is not present due to the direction of the synoptic-scale airflow the front does not speed up as it approaches the Alps. In contrary, it is even slightly decelerated by latent heat exchange due to pre-frontal precipitation that decreases the cross-frontal temperature contrast.

The full variety of possible configurations of frontal orientation, supra-scale airflow direction and speed, and vertical temperature and humidity profiles within the air masses separated by the front could, of course, not be covered by the limited number of numerical simulations. Nevertheless, the few cases shown in this study already exhibit a couple of phenomena which are fre- 
quently observed in connection with cold fronts near the Alps. Synthetic assumptions, such as the elimination of the Alps or the exclusion of latent heat exchanges are valuable for elucidating principal mechanisms that influence the frontal behaviour in the area of interest.

Further numerical investigation are going on in order to clarify the interaction of foehn and cold fronts north of the Alps. Especially, the static stability of the air and the angle between the largescale flow and the main axis of the Alpine mountain range will be varied to generate different foehn scenarios. Another aspect of interest are inversions within the warm air mass. They produce a stable environment ahead of the front and sometimes hinder the foehn to penetrate through the surface layer. Such situations are critical with respect to air pollutions which are trapped beneath the inversion, but which will be removed by a cold front (cf. Hoinka and Rößler, 1987).

\section{Acknowledgement}

This study was partly supported by a grant of the "Deutsche Forschungsgemeinschaft" (DFG).

\section{References}

Bannon, P. R., 1984: Effects of stratification on surface frontogenesis: warm and cold fronts. J. Atmos. Sci., 41, 20212026.

Blackadar, A. K., 1962: The vertical distribution of wind and turbulent exchange in a neutral atmosphere. J. Geophys. Res., 67, 3095-3102.

Businger, J. A., Wyngaard, J. C., Izumi, Y., Bradley, E. F., 1971: Flux-profile relationships in the atmospheric surface layer. J. Atmos. Sci., 28, 181-189.

Bischoff-Gauss, I., Gross, G., 1989: Numerical studies on cold fronts. Part I: Gravity flows in a neutral and stratified atmosphere. Meteorol. Atmos. Phys., 40, 150-158.

Chang, C. H., 1977: Ice generation in clouds. M.S. thesis, Dept. Meteor., South Dakota School of Mines and Technology, Rapid City SD, U.S.A.

Davies, H. C., 1984: On the orographic retardation of a cold front. Beitr. Phys. Atmos., 57, 409-418.

Egger, J., Haderlein, K., 1987: Fronts near orography in a one-layer model. J. Met. Soc. Jap., spec. Vol. coll. pap. WMO/IUGG NWP Sympos., Tokyo, 4-8 August 1986, 757-766.

Egger, J., 1989: Föhn and Quasi-Stationary Fronts. Beitr. Phys. Atmosph., 62, 20-29

Garrat, J. R., Physick, W. L., 1986: Numerical study of atmospheric gravity currents. I: Simulations and observations of cold fronts. Beitr. Phys. Atmosph., 59, 282300.

Gross, G., Wippermann, F., 1987: Channeling and countercurrent in the upper Rhine valley: numerical simulations. J. Climate Appl. Meteor., 26, 1293-1304.
Hagen, M., 1989: Wind Field and Precipitation Observations of a Narrow Cold-Frontal Rainband. Preprint Vol. 24th Conf. Radar Meteorol., March 27-31, 1989 Thallahassee FA, U.S.A.

Heimann, D., Volkert, H., 1988: The "papal front" of 3 May 1987: mesoscale analyses of routine data. Beitr. Phys. Atmosph., 61, 62-68.

Heimann, D., 1988: The "papal front" of 3 May 1987: modelling of orographic and diabatic effects. Beitr. Phys. Atmosph., 61, 330-343.

Höller, H., 1986: Parameterization of cloud-microphysical processes in a three-dimensional convective mesoscale model. DFVLR-FB 86-02, 82 p., obtainable from: Berichtswesen der DLR, Postfach 906058, D-5000 Köln 90, F.R.G.

Hoinka, K. P., 1985: On fronts in Central Europe. Beitr. Phys. Atmosph., 58, 560-571.

Hoinka, K. P., Smith, R. K., 1986: A Questionaire on Cold Fronts in Alpine Regions. DFVLR-Mitt. 86-02, obtainable from Wissenschaftliches Berichtswesen der DLR, POB 906058, D-5000 Köln 90, F.R.G.

Hoinka, K. P., Volkert, H., 1987: The German Front Experiment 1987. Bull. Amer. Meteor. Soc., 68, 1424-1427.

Hoinka, K. P., Volkert, H., Heimann, D., 1988: The German Front Experiment 1987: Observations and Preliminary Results. DFVLR-FB 88-21, 133 p., obtainable from: Berichtswesen der DLR, Postfach 906058, D-5000 Köln 90, F.R.G.

Hoinka, K. P., Hagen, M., Volkert, H., Heimann, D., 1990 : On the influence of the Alps on a cold front. Tellus, $42 \mathrm{~A}$, 140-164.

Huber-Pock, F., Kress, C., 1989: An operational model of objective frontal analysis based on ECMWF products. Meteorol. Atmos. Phys., 40, 170-180.

Kessler, E., 1969: On the distribution and continuity of water substance in atmospheric circulations. Meteor. Monogr., 10, 1-84.

Kurz, M., 1984: Frontogenese und Zyklogenese nördlich der Alpen. In: Conf. Paper XVIII. International Conference for Alpine Meteorology, 25-29. 9. 1984, Opatija/SFRJ, Zbornik-Meteorologskih i Hidroloskih Radova, 10, Beo$\operatorname{grad} /$ SFRJ

Kurz, M., 1989: Zur Analyse und Diagnose der ersten beiden Fronten des Frontexperiments der Deutschen Forschungsgemeinschaft (DFG). Meteorol. Rdsch., 41, 147160 .

Lin, Y.-L., Farley, R. D., Orville, H. D., 1983: Bulk parameterization of the snow field in a cloud model. J. Climate Appl. Meteor., 22, 1065-1092.

Mahrer, Y., Pielke, R. A., 1978: A test of an upstream spline interpolation technique for the advective terms in a numerical mesoscale model. Mon. Wea. Rev., 106, 818-830.

Orlanski, I., 1975: A rational subdivision of scales for atmospheric processes. Bull. Amer. Meteor. Soc., 56, 527534.

Orville, H. D., 1980: Numerical modeling of clouds in: Lecture notes IFAORS Short Course 450 on clouds: their formation, properties and effects. Williamsburg, Virginia, U.S.A., Dec. 1-5, 1980.

Pielke, R. A., 1984: Mesoscale meteorological modeling. Academic Press, Orlando FA, U.S.A. 
Renard, R. J., Clarke, L. C., 1965: Experiments in numerical objective frontal analysis. Mon. Wea. Rev., 93, 547-556.

Schumann, U., 1987: Influence of mesoscale orography on idealized cold fronts. J. Atmos. Sci., 44, 3423-3441.

Steinacker, R., 1981 : Analysis of the Temperature and Wind Field in the Alpine Region. Geophys. Astrophys. Fluid Dyn., 17, 51-62.

Stern, M. E., Whitehead, J. A., Hua, B.-L., 1982: The intrusion of a density current along the coast of a rotating fluid. J. Fluid Mech., 123, 237-265.
Volkert, H., Weickmann, L., Tafferner, A., 1990: The papal front of 3 May 1987-a remarkable example of frontogenesis near the Alps, submitted to Quart. J. R. Meteor. Soc.

Yamada, T., 1983: Simulations of nocturnal drainage flows by a $q^{2} l$ turbulence closure model. $J$. Atmos. Sci., 40, 91106.

Author's address: Dr. Dietrich Heimann, Institut für Physik der Atmosphäre, DLR Oberpfaffenhofen, D-8031 Weßling, Federal Republic of Germany. 